ARTICLE

DOI: $10.1038 /$ s41467-018-06053-z

\title{
Realization of vertical metal semiconductor heterostructures via solution phase epitaxy
}

\author{
Xiaoshan Wang ${ }^{1}$, Zhiwei Wang ${ }^{1}$, Jindong Zhang ${ }^{1}$ Xiang Wang ${ }^{1}$, Zhipeng Zhang ${ }^{1}$, Jialiang Wang ${ }^{1}$, Zhaohua Zhu', \\ Zhuoyao Li1, Yao Liu1, Xuefeng Hu², Junwen Qiu², Guohua Hu (1) ${ }^{3}$, Bo Chen ${ }^{4}$, Ning Wang1,4, Qiyuan He${ }^{4}$,

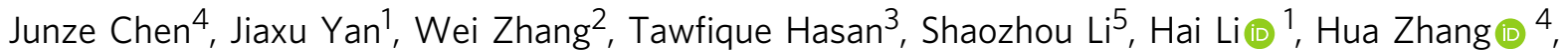 \\ Qiang Wang ${ }^{6}$, Xiao Huang $\mathbb{1}^{1} \&$ Wei Huang ${ }^{1,5,7}$
}

The creation of crystal phase heterostructures of transition metal chalcogenides, e.g., the $1 \mathrm{~T} / 2 \mathrm{H}$ heterostructures, has led to the formation of metal/semiconductor junctions with low potential barriers. Very differently, post-transition metal chalcogenides are semiconductors regardless of their phases. Herein, we report, based on experimental and simulation results, that alloying between $1 \mathrm{~T}-\mathrm{SnS}_{2}$ and $1 \mathrm{~T}-\mathrm{WS}_{2}$ induces a charge redistribution in $\mathrm{Sn}$ and $\mathrm{W}$ to realize metallic $\mathrm{Sn}_{0.5} \mathrm{~W}_{0.5} \mathrm{~S}_{2}$ nanosheets. These nanosheets are epitaxially deposited on surfaces of semiconducting $\mathrm{SnS}_{2}$ nanoplates to form vertical heterostructures. The ohmic-like contact formed at the $\mathrm{Sn}_{0.5} \mathrm{~W}_{0.5} \mathrm{~S}_{2} / \mathrm{SnS}_{2}$ heterointerface affords rapid transport of charge carriers, and allows for the fabrication of fast photodetectors. Such facile charge transfer, combined with a high surface affinity for acetone molecules, further enables their use as highly selective $100 \mathrm{ppb}$ level acetone sensors. Our work suggests that combining compositional and structural control in solution-phase epitaxy holds promises for solutionprocessible thin-film optoelectronics and sensors.

\footnotetext{
${ }^{1}$ Institute of Advanced Materials (IAM), Nanjing Tech University (NanjingTech), 30 South Puzhu Road, Nanjing 211816, China. ${ }^{2}$ State Key Laboratory of Materials-Oriented Chemical Engineering, College of Chemical Engineering, Nanjing Tech University (NanjingTech), 30 South Puzhu Road, Nanjing 211816, China. ${ }^{3}$ Cambridge Graphene Centre, University of Cambridge, Cambridge CB3 OFA, UK. ${ }^{4}$ Center for Programmable Materials, School of Materials Science and Engineering, Nanyang Technological University, 50 Nanyang Avenue, Singapore 639798, Singapore. ${ }^{5}$ Key Laboratory for Organic Electronics and Information Displays \& Institute of Advanced Materials, Jiangsu National Synergistic Innovation Center for Advanced Materials (SICAM), Nanjing University of Posts \& Telecommunications, 9 Wenyuan Road, Nanjing 210023, China. ${ }^{6}$ School of Chemistry and Molecular Engineering, Nanjing Tech University (NanjingTech), 30 South Puzhu Road, Nanjing 211816, China. ${ }^{7}$ Shaanxi Institute of Flexible Electronics (SIFE), Northwestern Polytechnical University (NPU), 127 West Youyi Road, Xi'an 710072, China. These authors contributed equally: Xiaoshan Wang, Zhiwei Wang. Correspondence and requests for materials should be addressed to Q.W. (email: wangqiang@njtech.edu.cn) or to X.H. (email: iamxhuang@njtech.edu.cn) or to W.H. (email: iamwhuang@nwpu.edu.cn)
} 
eterostructures constructed from layered materials such as graphene, metal chalcogenides and black phosphorus (BP) have aroused particular interest due to their combined advantageous features and the emergence of unusual properties/functions ${ }^{1-6}$. As a group of the mostly studied layered materials, transition metal chalcogenides (TMCs) like $\mathrm{MoS}_{2}$ and $\mathrm{WS}_{2}$ exist in different crystal phases such as the $2 \mathrm{H}$ and $1 \mathrm{~T}$ polytypes with distinct electronic properties. Their semiconductor-to-metal transition (i.e., $2 \mathrm{H}$-to-1T) can be realized via Li-intercalation, ${ }^{7}$ strain engineering, ${ }^{8}$ e-beam/laser irradiation $^{2}$ or doping/alloying ${ }^{2,7-9}$. This attractive feature allows for the formation of $2 \mathrm{H} / 1 \mathrm{~T}$ (semiconductor/metal) phase junctions that exhibit much reduced contact resistance compared to that of using noble metal contacts (e.g., $\mathrm{Au}$ ) which normally interface with semiconducting TMCs with large Fermi level misalignment ${ }^{2,10}$. Besides TMCs, post-TMCs such as $\mathrm{SnS}_{2}$ and InSe are another important group of layered materials, exhibiting attractive electronic and optoelectronic properties for a wide range of applications, including transistors, photodetectors, and sensors $^{11,12}$. Similar to many other semiconducting materials, the type of metal contact with post-TMCs plays a critical role in tuning their functional performance ${ }^{13}$. However, due to the less metallic nature of post-transition metals, post-TMCs are generally semiconductors regardless of their crystal phases, such as the $2 \mathrm{H}, 4 \mathrm{H}$, and $1 \mathrm{~T}$ polytypes ${ }^{14}$. Consequently, contacting postTMCs with metallic layered materials to achieve low interfacial resistance remains a big challenge.

To date, much effort has been devoted to the preparation of various heterostructures based on layered materials, which display different geometric arrangements such as the lateral and vertical heterostructures $1,3,15$. In particular, to prepare vertical heterostructures in which dissimilar layered crystals are stacked one above the other in a pre-designed sequence, solid-state procedures, including dry transfer, chemical vapor deposition (CVD) and chemical vapor transport (CVT) method have mostly been applied $3,16,17$. This is because these methods allow good control over the spatial arrangement of the layers as well as the deposition sequence. Compared to these solid-state methods, solutionphased approaches are advantageous in terms of relatively easier procedures, low-cost setups, and most importantly, scalability ${ }^{18,19}$. However, direct wet-chemical growth of vertical heterostructures of layered metal chalcogenides has thus far been challenging.

In view of their potential applications, heterostructures/heterojunctions such as InSe/graphene, $\mathrm{MoTe}_{2} / \mathrm{MoS}_{2}, \mathrm{MoS}_{2} /$ perovskite, and graphene/ $\mathrm{MoS}_{2} /$ graphene have recently shown promising performance in photodetectors, due to the improved charge separation/transport and enhanced light adsorption ${ }^{20-23}$. Meanwhile, development of gas sensors for detection of volatile organic compounds are important in applications such as environmental monitoring and non-invasive diagnosis of diseases based on breath analysis ${ }^{24,25}$. Chemiresistive sensors based on metal oxides/sulfides have been used for detection of volatile organic compounds, however, high operating temperatures (typically $\geq 150^{\circ} \mathrm{C}$ ) are usually required to achieve good sensitivity and selectivity ${ }^{24,26}$. Very recently, layered materials such as $\mathrm{SnS}_{2}$, $\mathrm{WS}_{2}$ and $\mathrm{Ti}_{3} \mathrm{C}_{2} \mathrm{~T}_{x}$ have demonstrated great potential for roomtemperature gas detection ${ }^{27-29}$. It is expected that creation of heterostructures may realize further improved sensing performance ${ }^{30-32}$.

In this contribution, nanoplates of $\mathrm{SnS}_{2}$, a typical n-type semiconductor, are used as synthesis templates for the surface deposition of layered $\mathrm{Sn}_{0.5} \mathrm{~W}_{0.5} \mathrm{~S}_{2}$ nanosheets, which show $83 \%$ metallic phase, leading to the formation of metal/semiconductor vertical heterostructures. Kelvin probe force microscope (KPFM) and tunneling atomic force microscopy (TUNA) analyses suggest the formation of ohmic-like contact at the $\mathrm{Sn}_{0.5} \mathrm{~W}_{0.5} \mathrm{~S}_{2} / \mathrm{SnS}_{2}$ interface. The resultant heterostructures are fabricated into chemiresistive sensors to detect acetone at room temperature and exhibit a good selectivity and a minimum detectable concentration down to $100 \mathrm{ppb}$. The good sensing performance could be attributed to the low charge transfer resistance at the $\mathrm{Sn}_{0.5} \mathrm{~W}_{0.5} \mathrm{~S}_{2} /$ $\mathrm{SnS}_{2}$ interface that enables a much increased signal-to-noise ratio, and the alloying induced enhancement in surface gas adsorption.

\section{Results}

Synthesis and characterizations of $\mathbf{S n}_{0.5} \mathbf{W}_{0.5} \mathrm{~S}_{2} / \mathrm{SnS}_{2}$. As a representative post-TMC, $\mathrm{SnS}_{2}$ has been widely studied and applied in phototransistors and sensors for its favorable band structure and relatively high surface electronegativity ${ }^{12,33}$. Typically, $\mathrm{SnS}_{2}$ nanoplates were synthesized via a hydrothermal reaction with thiourea $\left(\mathrm{CS}\left(\mathrm{NH}_{2}\right)_{2}\right)$ and tin tetrachloride hydrate $\left(\mathrm{SnCl}_{4} \bullet 5 \mathrm{H}_{2} \mathrm{O}\right)$ as the precursors for $\mathrm{S}$ and $\mathrm{Sn}$, respectively (see the Methods section for the detailed procedure $)^{34}$. As shown in the scanning electron microscope (SEM), transmission electron microscope (TEM) and atomic force microscopy (AFM) images in Supplementary Figs. 1 and 2, hexagonal nanoplates with edge lengths ranging from 200 to $700 \mathrm{~nm}$ and an average thickness of $43 \mathrm{~nm}$ were obtained. As confirmed by the selected area electron diffraction (SAED) and X-ray diffraction (XRD) analyses, the nanoplates are $\alpha-\mathrm{SnS}_{2}$ with a $1 \mathrm{~T}$ structure (space group $P \overline{3} \mathrm{~m} 1$ ), where $a=3.65$ and $c=5.90$ (ICSD no. 42566) ${ }^{12}$ (Supplementary Figs. $1 \mathrm{c}$ and d). By adding $\left(\mathrm{NH}_{4}\right)_{10} \mathrm{H}_{2}\left(\mathrm{~W}_{2} \mathrm{O}_{7}\right)_{6}$ to the precursors of the aforementioned synthesis solution, alloyed $\mathrm{Sn}_{1-x} \mathrm{~W}_{x} \mathrm{~S}_{2}$ nanosheets were in-situ synthesized and hybridized with $\mathrm{SnS}_{2}$ nanoplates as shown in Fig. 1a, b. These heterostructures show an average lateral size of $750 \mathrm{~nm}$ (Fig. 1a) and an average thickness of $60 \mathrm{~nm}$ (Fig. 1c and Supplementary Fig. 3). The side-view TEM image in Fig. 1d clearly shows a $\mathrm{SnS}_{2}$ nanoplate covered by $\mathrm{Sn}_{1-}$ ${ }_{x} \mathrm{~W}_{x} \mathrm{~S}_{2}$ nanosheets on both its basal faces forming a vertical heterostructure. The deposited $\mathrm{Sn}_{1-\mathrm{x}} \mathrm{W}_{\mathrm{x}} \mathrm{S}_{2}$ nanosheets are typically $6-9 \mathrm{~nm}$ in thickness (Supplementary Fig. 4). Energy dispersive X-ray spectroscopy (EDX) mapping of a typical heterostructure reveals the distribution of Sn, W, and S elements (Fig. 1e), in which the center of the heterostructure shows a higher concentration of Sn compared to the edge. EDX line analysis of the cross-section of a typical heterostructure, which was prepared by cutting with focused ion beam (FIB), further indicates that the $\mathrm{SnS}_{2}$ nanoplate was covered by $\mathrm{Sn}_{1-x} \mathrm{~W}_{x} \mathrm{~S}_{2}$ nanosheets (Fig. 1f). EDX spot analyses on edges of $\mathrm{Sn}_{1-x} \mathrm{~W}_{x} \mathrm{~S}_{2}$ nanosheets suggest $x \approx 0.5$, confirming $\mathrm{Sn}_{0.5} \mathrm{~W}_{0.5} \mathrm{~S}_{2}$ nanosheets were obtained (Supplementary Fig. 5).

The structural properties of the heterostructures were investigated with XRD and high resolution TEM (HRTEM) analysis. In the XRD pattern in Fig. 2a, besides the characteristic peaks for 1T$\mathrm{SnS}_{2}$, two relatively broader peaks observed at $8.9^{\circ}$ and $17.8^{\circ}$ could be attributed, respectively, to the (001) and (002) planes of $\mathrm{Sn}_{0.5} \mathrm{~W}_{0.5} \mathrm{~S}_{2}$ nanosheets with an enlarged interlayer spacing of about $1.0 \mathrm{~nm}$. The enlarged spacing, which was also observed in side-view HRTEM images (Supplementary Fig. 6), may result from the use of $\mathrm{CS}\left(\mathrm{NH}_{2}\right)_{2}$ and $\left(\mathrm{NH}_{4}\right)_{10} \mathrm{H}_{2}\left(\mathrm{~W}_{2} \mathrm{O}_{7}\right)_{6}$ in our synthesis, leading to the intercalation of $\mathrm{NH}_{4}{ }^{+}$ions in between the adjacent layers ${ }^{35}$. This was also confirmed by X-ray photoelectron spectroscopy (XPS) analysis (Supplementary Fig. 7). The crystal structure of a typical heterostructure was further investigated by taking its SAED pattern. As shown in Fig. 2b, two sets of patterns both along the [001] zone axis show the epitaxial registry. The hexagonal pattern with six inner and six outer spots can be assigned to $1 \mathrm{~T}-\mathrm{SnS}_{2}$, and the measured (100) lattice spacing is $3.16 \AA$, in good agreement with the XRD result (Fig. 2a). The other set of pattern for $\mathrm{Sn}_{0.5} \mathrm{~W}_{0.5} \mathrm{~S}_{2}$ shows elongated spots, forming discontinued ring segments. This may 

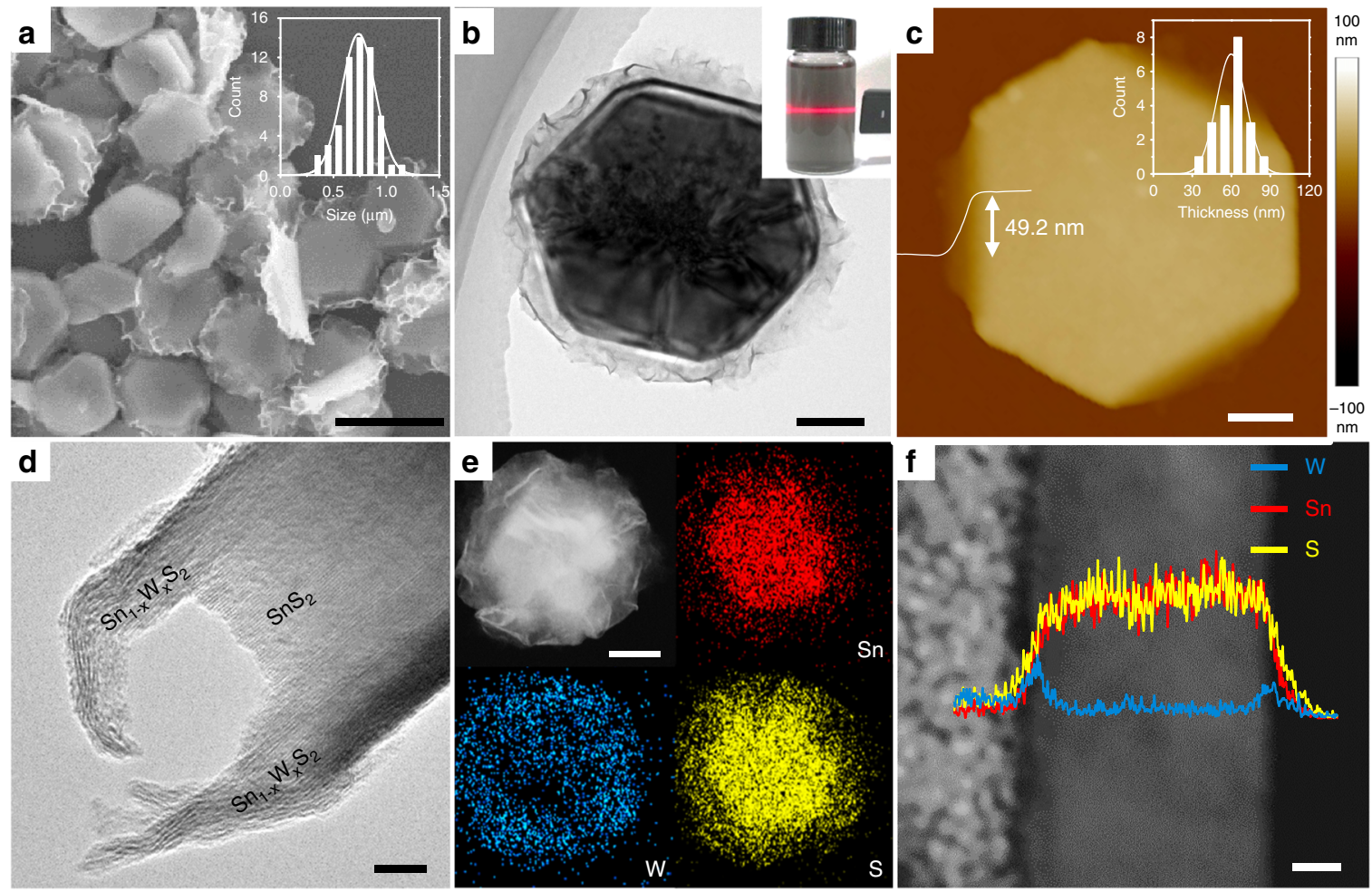

Fig. 1 Morphology and composition analyses of $\mathrm{Sn}_{0.5} \mathrm{~W}_{0.5} \mathrm{~S}_{2} / \mathrm{SnS}_{2}$ heterostructures. a SEM image of as-prepared $\mathrm{Sn}_{1-x} \mathrm{~W}_{x} \mathrm{~S}_{2} / \mathrm{SnS}_{2}$ heterostructures (scale bar, $1 \mu \mathrm{m}$ ). Inset: size distribution of $\mathrm{Sn}_{1-x} \mathrm{~W}_{x} \mathrm{~S}_{2} / \mathrm{SnS}_{2}$ heterstructures. b Top-view TEM image of typical $\mathrm{Sn}_{1-x} \mathrm{~W}_{x} \mathrm{~S}_{2} / \mathrm{SnS}_{2}$ heterostructures (scale bar, 200 $\mathrm{nm}$ ). Inset: photograph of a solution of $\mathrm{Sn}_{1-x} \mathrm{~W}_{x} \mathrm{~S}_{2} / \mathrm{SnS}_{2}$ heterostructures showing the Tyndall effect. $\mathbf{c} A F M$ image and height analysis of a $\mathrm{Sn}_{1-x} \mathrm{~W}_{x} \mathrm{~S}_{2} / \mathrm{SnS}_{2}$ heterostructure (scale bar, $100 \mathrm{~nm}$ ). Inset: thickness distribution of $\mathrm{Sn}_{1-x} \mathrm{~W}_{x} \mathrm{~S}_{2} / \mathrm{SnS}_{2}$ heterstructures, showing a mean value of $60 \mathrm{~nm}$. d Side-view TEM image of a typical $\mathrm{Sn}_{1-x} \mathrm{~W}_{x} \mathrm{~S}_{2} / \mathrm{SnS}_{2}$ heterostructure, revealing $\mathrm{Sn}_{1-x} \mathrm{~W}_{x} \mathrm{~S}_{2}$ nanosheets grown on both the top and bottom basal faces of a SnS $\mathrm{S}_{2}$ nanoplate (scale bar, $10 \mathrm{~nm}$ ). e STEM image and EDX mapping on a typical $\mathrm{Sn}_{1-x} \mathrm{~W}_{x} \mathrm{~S}_{2} / \mathrm{SnS}_{2}$ heterostructure (scale bar, $100 \mathrm{~nm}$ ). f Cross-sectional STEM image and EDX line analysis on a typical $\mathrm{Sn}_{1-x} \mathrm{~W}_{x} \mathrm{~S}_{2} / \mathrm{SnS}_{2}$ heterostructure (scale bar, $10 \mathrm{~nm}$ )

result from the curled structure of the $\mathrm{Sn}_{0.5} \mathrm{~W}_{0.5} \mathrm{~S}_{2}$ nanosheets as well as possible misorientation. The measured lattice spacing for $\mathrm{Sn}_{0.5} \mathrm{~W}_{0.5} \mathrm{~S}_{2}$ (100) planes was $3.0 \AA$, corresponding to a lattice parameter of $a=3.46 \AA$. This reasonably falls in between that of $\mathrm{WS}_{2}(a=3.16 \AA)$ and $\mathrm{SnS}_{2}(a=3.65 \AA)$. Note that the mismatch between the (100) planes of $\mathrm{SnS}_{2}$ and $\mathrm{Sn}_{0.5} \mathrm{~W}_{0.5} \mathrm{~S}_{2}$ is $5 \%$, which can be tolerated in van der Waals epitaxial growth of layered materials ${ }^{36}$. The top-view HRTEM image in Fig. $2 c$ distinctly shows the relatively darker region for the $\mathrm{SnS}_{2}$ nanoplate covered with $\mathrm{Sn}_{0.5} \mathrm{~W}_{0.5} \mathrm{~S}_{2}$, and the brighter region for the periphery $\mathrm{Sn}_{0.5} \mathrm{~W}_{0.5} \mathrm{~S}_{2}$ nanosheet. The lattice fringes extend continuously from the $\mathrm{SnS}_{2} / \mathrm{Sn}_{0.5} \mathrm{~W}_{0.5} \mathrm{~S}_{2}$ center to the $\mathrm{Sn}_{0.5} \mathrm{~W}_{0.5} \mathrm{~S}_{2}$ edge, further confirming the epitaxial growth mode. Moiré patterns could be observed in some areas due to the overlap of $\mathrm{Sn}_{0.5} \mathrm{~W}_{0.5} \mathrm{~S}_{2}$ and $\mathrm{SnS}_{2}$ at small misorientation angles. For example, as shown in Fig. 2d, a Moiré pattern with a periodicity of $4.0 \mathrm{~nm}$ was observed when the $\mathrm{Sn}_{0.5} \mathrm{~W}_{0.5} \mathrm{~S}_{2}$ overlayer made a misorientation angle of $3^{\circ}$ with $\mathrm{SnS}_{2}$ (see the detailed analysis in Supplementary Fig. 8). Note that the overlapping of two hexagonal lattice patterns normally produces a hexagonal Moiré pattern ${ }^{37}$, which was not observed in the present work. This may be due to the fact that the $\mathrm{Sn}_{0.5} \mathrm{~W}_{0.5} \mathrm{~S}_{2}$ nanosheets showed lattice distortion with varied interlayer spacings (0.6-1.0 $\mathrm{nm}$, Supplementary Fig. 6), and thus were deviated from being perfectly flat on the $\mathrm{SnS}_{2}$ nanoplate. As a result, only short-range line-like Moiré patterns were observed ${ }^{38}$. High resolution scanning TEM (STEM) images of the edge area of a heterostructure show the 1T-phase-like atomic arrangement of $\mathrm{Sn}_{0.5} \mathrm{~W}_{0.5} \mathrm{~S}_{2}$ (Supplementary Fig. 9) $)^{39}$. It is interesting that zigzag lattice patterns for $1 \mathrm{~T}^{\prime}$ or $\mathrm{T}_{\mathrm{d}}$ phases which have been previously observed in TMCs such as $\mathrm{WS}_{2}$ and $\mathrm{WTe}_{2}{ }^{40,41}$ were not observed in $\mathrm{Sn}_{0.5} \mathrm{~W}_{0.5} \mathrm{~S}_{2}$. Based on our density functional theory (DFT) calculation results shown in Supplementary Table 1 and Supplementary Fig. 10, the W-S bonds tend to be shorter than the Sn-S bonds in the alloyed system, resulting in a distortion from the perfect in-plane symmetric $1 \mathrm{~T}$ lattice. The distorted 1T structure was also reflected in the Raman spectrum in Supplementary Fig. 11, where in addition to the peaks at 310,351 , and $414 \mathrm{~cm}^{-1}$ that correspond to the $\mathrm{SnS}_{2}$-like $A_{1 \mathrm{~g}}$, $\mathrm{WS}_{2}$-like $E_{2 \mathrm{~g}}$ and $\mathrm{WS}_{2}$-like $A_{1 \mathrm{~g}}$ modes, respectively, the active modes observed at $171 \mathrm{~cm}^{-1}$ and $224 \mathrm{~cm}^{-1}$ in the lower frequency region could be attributed to distorted $1 \mathrm{~T}-\mathrm{WS}_{2}{ }^{12,35}$. The dominant distorted 1T-phased W-S coordination was further confirmed by XPS analysis (Fig. 2e). It has been reported that the XPS band positions of a metal element are sensitive to their oxidation states, coordination geometries, and Fermi levels ${ }^{42,43}$. Normally in the $\mathrm{W} f$ spectrum, the doublet peaks ( 32.1 and $34.2 \mathrm{eV}$ ) associated with $\mathrm{W}$ in the $1 \mathrm{~T}$-phased structure are downshifted by $0.6 \mathrm{eV}$ relative to those associated with $\mathrm{W}$ in the $2 \mathrm{H}$ structure $(32.7$ and $34.8 \mathrm{eV})$. The deconvolution of the $\mathrm{W} 4 \mathrm{f}$ bands thus could enable the quantitative estimation of the $1 \mathrm{~T}$ and $2 \mathrm{H}$ phase concentrations ${ }^{7}$. In our case, from the deconvoluted peak areas (Fig. 2e), the concentrations of the distorted $1 \mathrm{~T}$ and $2 \mathrm{H}$ phases were calculated to be $83 \%$ and $17 \%$, respectively. For the Sn $3 d$ spectrum, the peak positions match well with the $1 \mathrm{~T}-\mathrm{SnS}_{2}$ structure (Fig. $\left.2 \mathrm{f}\right)^{44}$.

The formation of $1 \mathrm{~T}$ or distorted $1 \mathrm{~T}$ structures have been observed previously in TMCs when they were intercalated with alkali metal ions (e.g., $\mathrm{Li}^{+}, \mathrm{K}^{+}$etc. $)^{39,45}$ or synthesized in the 

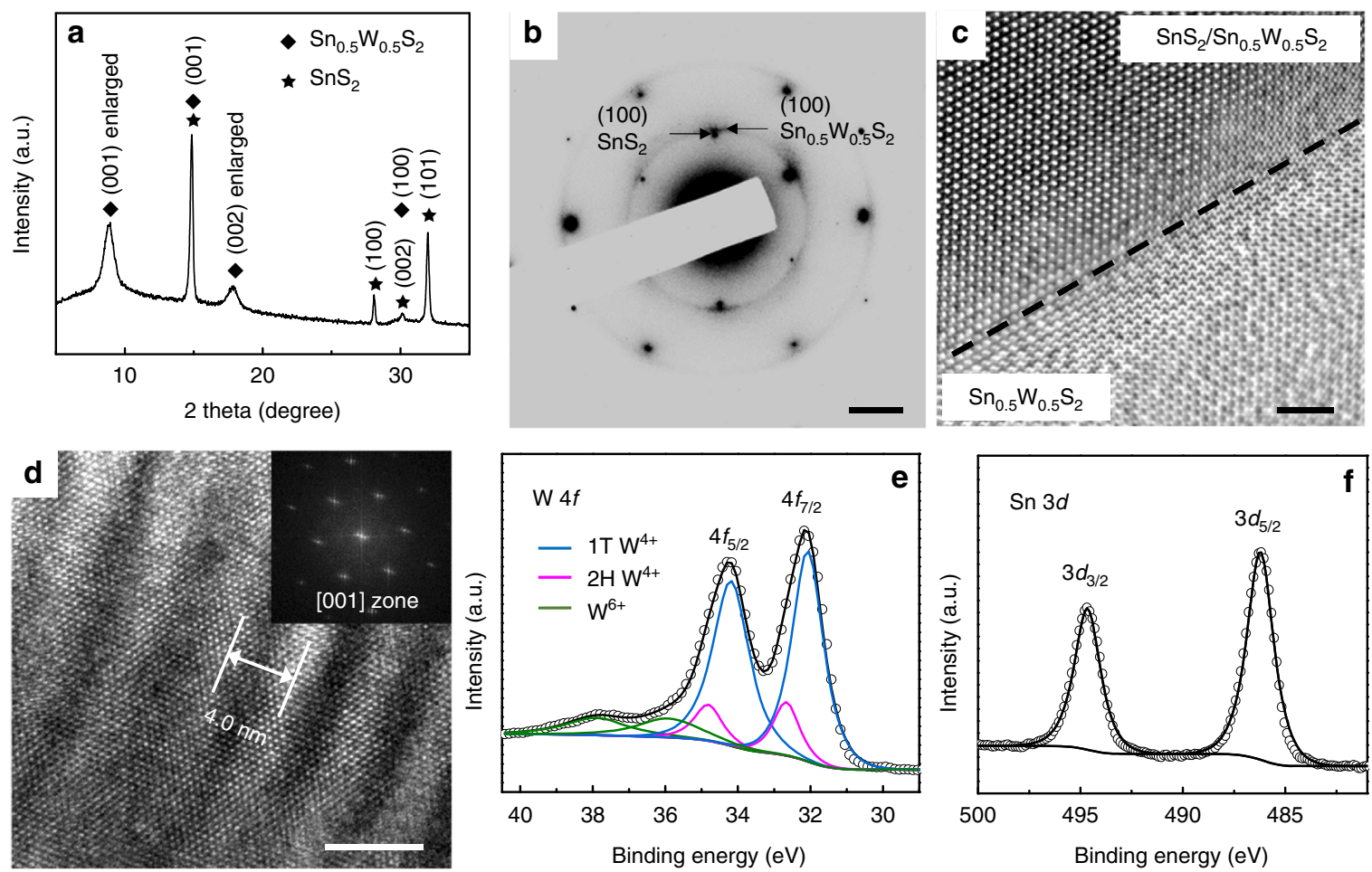

Fig. 2 Structural properties of $\mathrm{Sn}_{0.5} \mathrm{~W}_{0.5} \mathrm{~S}_{2} / \mathrm{SnS}_{2}$ heterostructures. a XRD pattern of $\mathrm{Sn}_{0.5} \mathrm{~W}_{0.5} \mathrm{~S}_{2} / \mathrm{SnS}_{2}$ heterostructures deposited on a glass slide. b SAED patterns of a $\mathrm{Sn}_{0.5} \mathrm{~W}_{0.5} \mathrm{~S}_{2} / \mathrm{SnS}_{2}$ heterostructure along the [001] zone axis (scale bar, $2 \mathrm{~nm}^{-1}$ ). c HRTEM image of a typical $\mathrm{Sn}_{0.5} \mathrm{~W}_{0.5} \mathrm{~S}_{2} / \mathrm{SnS}_{2}$ heterostructure lying flatly on a copper grid (scale bar, $2 \mathrm{~nm}$ ). d A Moiré pattern with a periodicity of $4.0 \mathrm{~nm}$ was observed (scale bar, $5 \mathrm{~nm}$ ), whose fast Fourier transform (FFT) diffraction pattern is shown as the inset. XPS (e) W $4 f$ and $\mathbf{f} \mathrm{Sn} 3 d$ spectra of as-prepared $\mathrm{Sn}_{0.5} \mathrm{~W}_{0.5} \mathrm{~S}_{2} / \mathrm{SnS}_{2}$ heterostructures

presence of ammonium containing precursors ${ }^{35}$ and hydrazine hydrate $^{46}$. According to previous theoretical calculations, the presence of the positive counterions could cause an increase of the electron density of the $d$-orbital of the transition metals, leading to the stabilization of the $1 \mathrm{~T}$ or distorted $1 \mathrm{~T}$ phase $\mathrm{e}^{47}$. Therefore, the realization of the distorted $1 \mathrm{~T}-\mathrm{Sn}_{0.5} \mathrm{~W}_{0.5} \mathrm{~S}_{2}$ in our present work might also be a result of the intercalated $\mathrm{NH}_{4}{ }^{+}$ cations from $\mathrm{CS}\left(\mathrm{NH}_{2}\right)_{2}$ and $\left(\mathrm{NH}_{4}\right)_{10} \mathrm{H}_{2}\left(\mathrm{~W}_{2} \mathrm{O}_{7}\right)_{6}$ used in the synthesis solution.

Formation process of $\mathbf{S n}_{\mathbf{0 . 5}} \mathbf{W}_{\mathbf{0 . 5}} \mathbf{S}_{\mathbf{2}} / \mathrm{SnS}_{\mathbf{2}}$. To investigate the formation process of the $\mathrm{Sn}_{0.5} \mathrm{~W}_{0.5} \mathrm{~S}_{2} / \mathrm{SnS}_{2}$ vertical heterostructures, intermediate products were collected at different reaction intervals for characterizations. At the beginning of the synthesis process, the precursors, i.e., $\left(\mathrm{NH}_{4}\right)_{10} \mathrm{H}_{2}\left(\mathrm{~W}_{2} \mathrm{O}_{7}\right)_{6}$ and $\mathrm{SnCl}_{4} \cdot 5 \mathrm{H}_{2} \mathrm{O}$, reacted to produce $\mathrm{Sn}\left(\mathrm{HWO}_{4}\right)_{2} \bullet n \mathrm{H}_{2} \mathrm{O}$ amorphous particles upon mixing at $80^{\circ} \mathrm{C}$ (Supplementary Fig. 12) ${ }^{48}$, which were subsequently heated up to $220^{\circ} \mathrm{C}$ under hydrothermal conditions. After the reaction had proceeded for $12 \mathrm{~h}$ at $220^{\circ} \mathrm{C}$, nanorods with lengths of $10-100 \mathrm{~nm}$ were observed together with $\mathrm{SnS}_{2}$ nanoplates in the solution (Fig. 3a, b). These nanorods are alloyed oxide of $\mathrm{Sn}$ and $\mathrm{W}$ with a formula of $\mathrm{Sn}_{0.17} \mathrm{WO}_{3}$ based on XRD pattern (ICSD No. 38043 [https://icsd.fiz-karlsruhe.de], Fig. 3c) ${ }^{49}$, EDX analysis (Supplementary Fig. 13a, b) and HRTEM imaging (Supplementary Fig. 13c). The reason why $\mathrm{WS}_{2}$ was not produced at this stage is that the bond energy of $\mathrm{Sn}-\mathrm{S}$ was likely to be lower than that of $\mathrm{W}-\mathrm{S}$ due to the larger ionic radius of $\mathrm{Sn}^{4+}$ compared to that of $\mathrm{W}^{4+50,51}$. As the reaction proceeded further, the amount of the $\mathrm{Sn}_{0.17} \mathrm{WO}_{3}$ nanorods decreased, and nanosheets started to form on the surfaces of the $\mathrm{SnS}_{2}$ nanoplates (Supplementary Fig. 14). Evidently, the evolution of the XRD patterns of the intermediate products indicates a decrease of the $\mathrm{Sn}_{0.17} \mathrm{WO}_{3}$ amount over time (Fig. 3c), which is accompanied with an increase of the Sn and $\mathrm{W}$ ion concentration in the solution based on the inductively coupled plasma mass spectrometry (ICP-MS) measurements (Supplementary Table 2). Based on our control experiments, $\mathrm{Sn}_{0.17} \mathrm{WO}_{3}$ nanorods could form at $180{ }^{\circ} \mathrm{C}$ and decompose at temperatures above $200{ }^{\circ} \mathrm{C}$ (Supplementary Fig. 15). This suggests that the $\mathrm{Sn}_{0.17} \mathrm{WO}_{3}$ nanorods forming at the beginning of the hydrothermal reaction gradually decomposed at $220^{\circ} \mathrm{C}$ (step 1 in Fig. 3d), providing additional $\mathrm{Sn}$ and $\mathrm{W}$ ions with a high $\mathrm{W} / \mathrm{Sn}$ ratio ( $>30$ ) (Supplementary Table 2). Such a high W/Sn ratio could drive the growth of alloyed $\mathrm{Sn}_{0.5} \mathrm{~W}_{0.5} \mathrm{~S}_{2}$ nanosheets on the surface of $\mathrm{SnS}_{2}$ even though the formation of $\mathrm{W}-\mathrm{S}$ bond is less favored compared to that of the $\mathrm{Sn}-\mathrm{S}$ bond (step 2 in Fig. 3d). In addition, we also tried to extend the Sn-W binary system to $\mathrm{Sn}-\mathrm{Mo}$ system, but found that, under certain conditions, $\mathrm{Sn}_{1-x} \mathrm{Mo}_{x} \mathrm{~S}_{2}$ nanosheets grew epitaxially on $\mathrm{SnS}_{2}$ mainly via the edge growth. This phenomenon might be due to the different synthesis energies required for basal growth or edge growth ${ }^{3}$, which requires our further investigation.

Electronic properties of $\mathbf{S n}_{\mathbf{0 . 5}} \mathbf{W}_{\mathbf{0 . 5}} \mathrm{S}_{\mathbf{2}} / \mathrm{SnS}_{\mathbf{2}}$. Alloying has been a powerful approach to tune the bandgaps of TMCs or to achieve their semiconductor-to-metal transitions ${ }^{9,52}$. However, alloying between layered TMC and post-TMC has not been reported so far, and thus the electronic properties of such alloys could be of great interest for potential applications. DFT calculations were performed to understand the electronic properties of the distorted $1 \mathrm{~T}-\mathrm{Sn}_{0.5} \mathrm{~W}_{0.5} \mathrm{~S}_{2}$ deposited on $1 \mathrm{~T}-\mathrm{SnS}_{2}$ with and without $\mathrm{NH}_{4}{ }^{+}$ intercalation. The detailed results of the optimized crystal structures, calculated Bader charges, band structures and density of states (DOS) are shown in Fig. 4, Supplementary Figs 16 and 17 and Supplementary Table 1. In contrast to a five-layer semiconducting $1 \mathrm{~T}-\mathrm{SnS}_{2}$ which shows no DOS at the Fermi level (Fig. 4b), a four-layer distorted $1 \mathrm{~T}-\mathrm{Sn}_{0.5} \mathrm{~W}_{0.5} \mathrm{~S}_{2}$ on a monolayer 

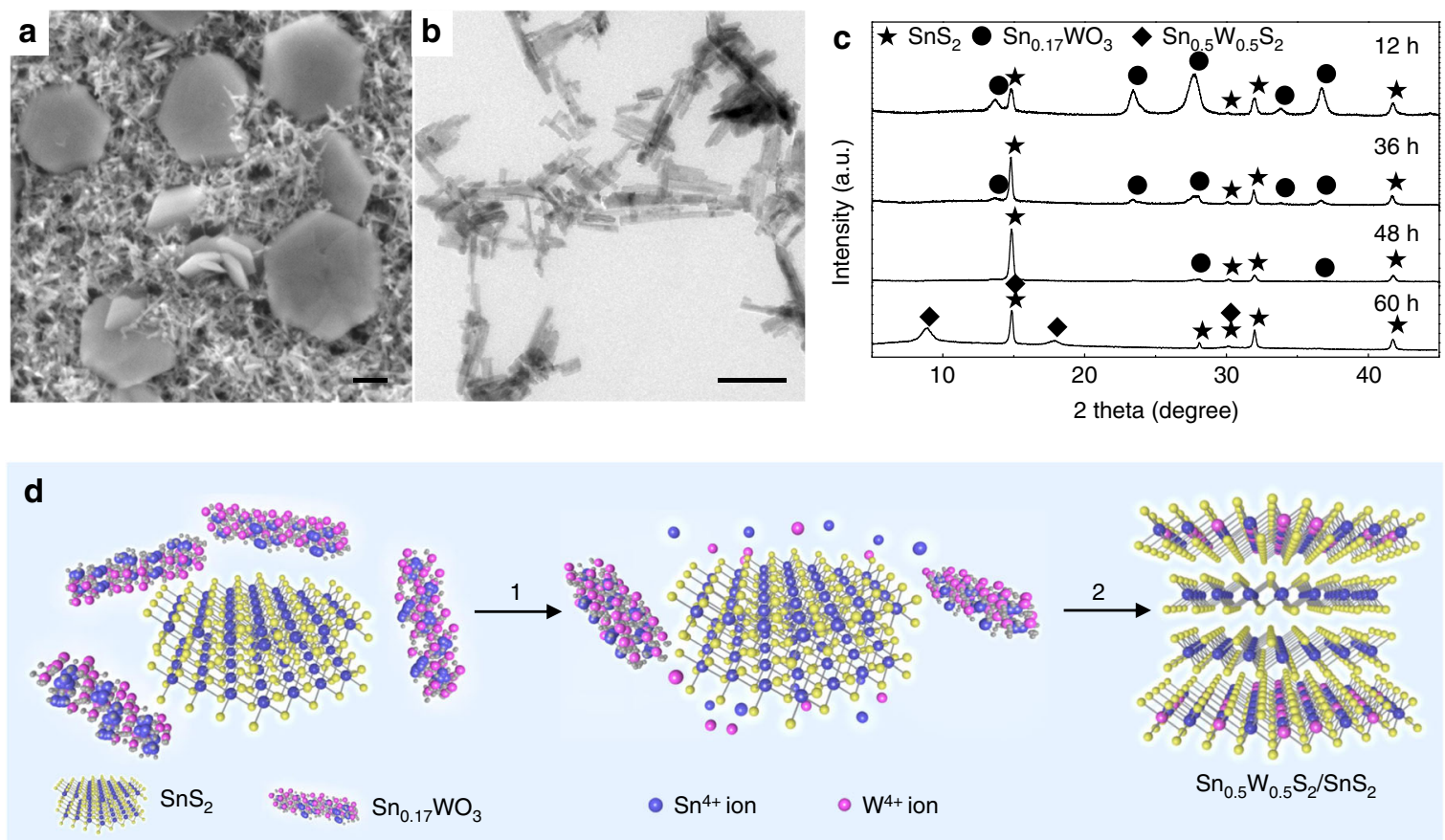

Fig. 3 Formation process of $\mathrm{Sn}_{0.5} \mathrm{~W}_{0.5} \mathrm{~S}_{2} / \mathrm{SnS}_{2}$ heterostructures. a SEM image of the intermediate product obtained after the reaction proceeded for $12 \mathrm{~h}$ (scale bar, $200 \mathrm{~nm}$ ). b TEM image of typical $\mathrm{Sn}_{0.17} \mathrm{WO}_{3}$ nanorods (scale bar, $100 \mathrm{~nm}$ ). c XRD patterns of the intermediate products obtained at different reaction intervals. $d$ Schematic illustration of the formation process of $\mathrm{Sn}_{0.5} \mathrm{~W}_{0.5} \mathrm{~S}_{2} / \mathrm{SnS}_{2}$ heterostructures. $\mathrm{SnS}_{2}$ nanoplates and $\mathrm{Sn}_{0.17} \mathrm{WO}_{3}$ nanorods formed together during the initial $12 \mathrm{~h}$. After that the $\mathrm{Sn}_{0.17} \mathrm{WO}_{3}$ nanorods began to decompose (step 1), providing additional $\mathrm{W}$ and $\mathrm{Sn}$ ions for $\mathrm{Sn}_{0.5} \mathrm{~W}_{0.5} \mathrm{~S}_{2}$ nanosheets to grow on the surfaces of the $\mathrm{SnS}_{2}$ nanoplates (step 2)

$1 \mathrm{~T}-\mathrm{SnS}_{2}$ exhibits intrinsic metallic behavior with observable DOS at the Fermi level, dominantly contributed from the $\mathrm{W}$ and $\mathrm{S}$ atoms and slightly from the Sn atoms (Fig. 4d). The calculated Bader charge of $\mathrm{W}$ atoms in distorted $1 \mathrm{~T}-\mathrm{Sn}_{0.5} \mathrm{~W}_{0.5} \mathrm{~S}_{2}$ is $0.20 \mathrm{e}$ higher compared to that in $1 \mathrm{~T}-\mathrm{WS}_{2}$, whereas the Bader charge of Sn atoms in distorted $1 \mathrm{~T}-\mathrm{Sn}_{0.5} \mathrm{~W}_{0.5} \mathrm{~S}_{2}$ is 0.10 e lower compared to that in $1 \mathrm{~T}-\mathrm{SnS}_{2}$ (Fig. 4a, c and Supplementary Fig. 16). This suggests a charge redistribution in the $\mathrm{Sn}_{0.5} \mathrm{~W}_{0.5} \mathrm{~S}_{2}$ alloy by charge transfer from $\mathrm{W}$ to $\mathrm{Sn}$ atoms ${ }^{53}$. Similarly, the distorted 1T$\mathrm{Sn}_{0.5} \mathrm{~W}_{0.5} \mathrm{~S}_{2}$ with intercalated $\mathrm{NH}_{4}{ }^{+}$ions $(20 \mathrm{~mol} \%)$ also shows the metallic behavior (Supplementary Fig. 17). To experimentally verify the calculated results, the electronic properties of the $\mathrm{SnS}_{2}$ nanoplates and $\mathrm{Sn}_{0.5} \mathrm{~W}_{0.5} \mathrm{~S}_{2} / \mathrm{SnS}_{2}$ heterostructures were measured by fabrication of back-gated thin film field effect transistors (Supplementary Fig. 18). The drain current $\left(I_{\mathrm{d}}\right)$ vs. drain-source voltage $\left(V_{\mathrm{ds}}\right)$ curves at varied gate voltages reveal that the $\mathrm{SnS}_{2}$ nanoplates are typical n-type semiconductors (Supplementary Fig. $18 \mathrm{a}, \mathrm{b})^{12}$. In contrast, the $I-V$ curves of films prepared from $\mathrm{Sn}_{0.5} \mathrm{~W}_{0.5} \mathrm{~S}_{2} / \mathrm{SnS}_{2}$ heterostructures are almost insensitive to gate voltages (Supplementary Fig. 18c, d), suggesting the metallic charge transport through the $\mathrm{Sn}_{0.5} \mathrm{~W}_{0.5} \mathrm{~S}_{2}$ nanosheets, consistent with the theoretical predictions.

To exmamine the interface property between a $\mathrm{SnS}_{2}$ nanoplate and the surface deposited $\mathrm{Sn}_{0.5} \mathrm{~W}_{0.5} \mathrm{~S}_{2}$, its surface potential, which corelates to its work function, was analyzed by KPFM in $\operatorname{air}^{21}$. A PtIr tip was used as the probe, and a $\mathrm{SiO}_{2} / \mathrm{Si}$ substrate sputtered with $\mathrm{Au} / \mathrm{Cr}$ with a theoretical work function $\left(\phi_{\mathrm{Au}}\right)$ of $5.100 \mathrm{eV}$ was used as the potential reference. The $2 \mathrm{D}$ potential image of a typical $\mathrm{Sn}_{0.5} \mathrm{~W}_{0.5} \mathrm{~S}_{2} / \mathrm{SnS}_{2}$ heterostructure is shown in Fig. 5a, where the color variation reflects the local surface potential difference $(\Delta V=$ $\phi_{\mathrm{Au}}-\phi_{\text {sample }}$ ) (details on the calculation of the surface potentials are given in the Methods section). It can be seen that the surface potential of the $\mathrm{Sn}_{0.5} \mathrm{~W}_{0.5} \mathrm{~S}_{2} / \mathrm{SnS}_{2}$ heterostructure is $0.029 \mathrm{~V}$ lower than that of Au to give an estimated work function of $5.071 \mathrm{eV}$ (Fig. 5a). On the other hand, an $\mathrm{SnS}_{2}$ nanoplate exhibits a work function of $5.110 \mathrm{eV}$ (Fig. 5b). The decrease in surface potential after deposition of $\mathrm{Sn}_{0.5} \mathrm{~W}_{0.5} \mathrm{~S}_{2}$ on $\mathrm{SnS}_{2}$ suggests that the metallic $\mathrm{Sn}_{0.5} \mathrm{~W}_{0.5} \mathrm{~S}_{2}$ possesses a lower work function than that of the $\mathrm{n}$ type $\mathrm{SnS}_{2}$. Although based on DFT calcuations, the work function of distorted $1 \mathrm{~T}-\mathrm{Sn}_{0.5} \mathrm{~W}_{0.5} \mathrm{~S}_{2}$ is $5.62 \mathrm{eV}$ which is much higher than that of $\mathrm{SnS}_{2}$, it can be substantially lowered to $2.87 \mathrm{eV}$ by introducing an $\mathrm{NH}_{4}{ }^{+}$intercalation with a molar concentration of about $20 \%$ (Supplementary Table 1). Such work function modulation induced by doping or chemical absorbates has also been reported previously ${ }^{54}$. This also explains why the experimentally measured work function of $\mathrm{Sn}_{0.5} \mathrm{~W}_{0.5} \mathrm{~S}_{2}$ nanosheets with partial $\mathrm{NH}_{4}{ }^{+}$intercalation was lower than that of $\mathrm{SnS}_{2}$. Therefore, an ohmic contact should form at the $\mathrm{Sn}_{0.5} \mathrm{~W}_{0.5} \mathrm{~S}_{2} / \mathrm{SnS}_{2}$ heterointerface (Fig. 5c), affording a low charge transfer resistance. This was further confirmed by measuring $I-V$ curves on individual $\mathrm{SnS}_{2}$ nanoplates or $\mathrm{Sn}_{0.5} \mathrm{~W}_{0.5} \mathrm{~S}_{2} / \mathrm{SnS}_{2}$ heterostructures deposited on highly oriented pyrolytic graphite (HOPG) with TUNA (Fig. 5d, e). The $I-V$ curve for a $\mathrm{SnS}_{2}$ nanoplate is highly asymmetric and the onset of the current rectification is at $3.50 \mathrm{~V}$ (Fig. 5d), indicating the presence of Schottky barrier at the PtIr tip/n-type $\mathrm{SnS}_{2}$ interface, provided that the work function for PtIr, $\mathrm{HOPG}$, and $\mathrm{SnS}_{2}$ is $5.50,4.60$, and $5.11 \mathrm{eV}$, respectively ${ }^{55,56}$. In sharp contrast, the $I-V$ curve for $\mathrm{Sn}_{0.5} \mathrm{~W}_{0.5} \mathrm{~S}_{2} / \mathrm{SnS}_{2}$ is almost linear and symmetric with respect to $0 \mathrm{~V}$, suggesting that the contact at $\mathrm{SnS}_{2} / \mathrm{Sn}_{0.5} \mathrm{~W}_{0.5} \mathrm{~S}_{2}$ interface is ohmic-like (Fig. $\left.5 \mathrm{e}\right)^{57}$.

$\mathrm{Sn}_{\mathbf{0 . 5}} \mathrm{W}_{\mathbf{0 . 5}} \mathrm{S}_{2} / \mathrm{SnS}_{2}$ for photodetectors. The advantage of the facile charge transport across the ohmic-like heterointerfaces was demonstrated in fabrication of thin film photodetectors based on the $\mathrm{Sn}_{0.5} \mathrm{~W}_{0.5} \mathrm{~S}_{2} / \mathrm{SnS}_{2}$ heterostructures. Figure 6a shows the $I-V$ curves of the device under $405 \mathrm{~nm}$ laser illumination with power 
a

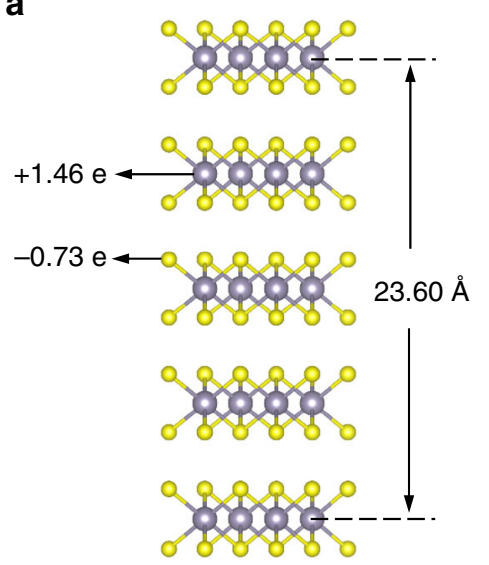

C
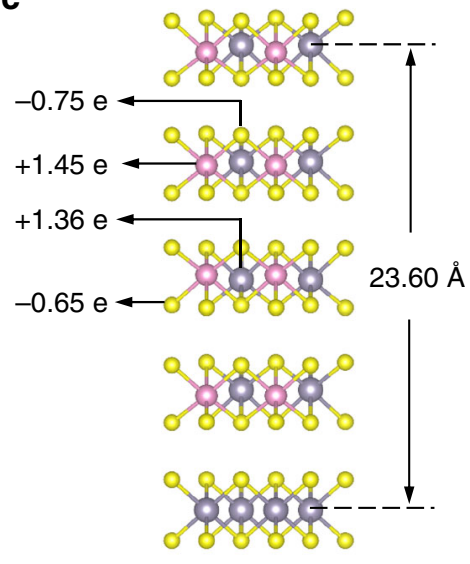

b

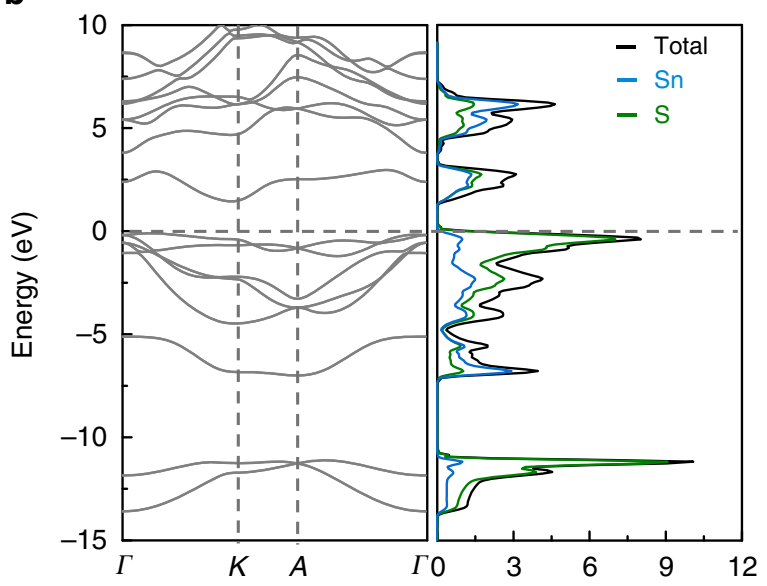

d

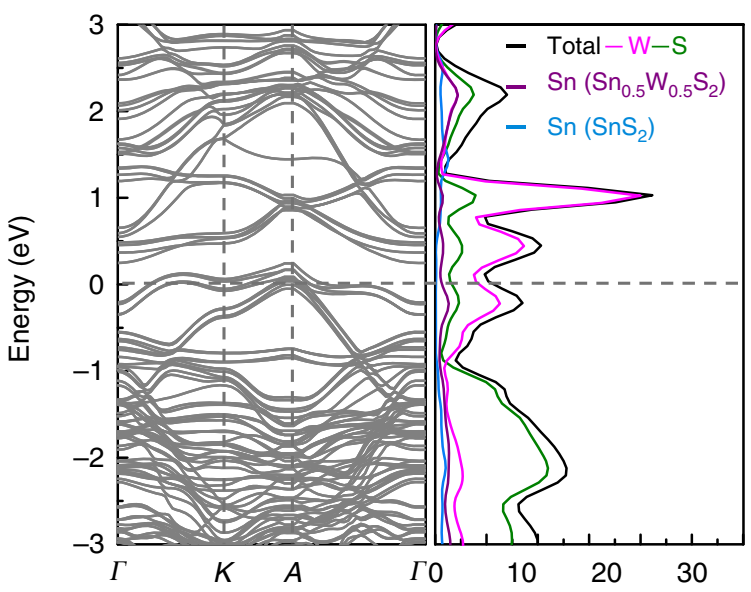

Fig. 4 Calculated electronic structure of $\mathrm{SnS}_{2}$ and $\mathrm{Sn}_{0.5} \mathrm{~W}_{0.5} \mathrm{~S}_{2} / \mathrm{SnS}_{2}$ heterostructures. a Optimized crystal structure with calculated Bader charges. b Band structure and DOS of a 5-layer $\mathrm{SnS}_{2}$, showing an indirect band gap near the Fermi level. c Optimized crystal structure with calculated Bader charges. d Band structure and DOS of a four-layer $1 \mathrm{~T}-\mathrm{Sn}_{0.5} \mathrm{~W}_{0.5} \mathrm{~S}_{2}$ on a monolayer $1 \mathrm{~T}-\mathrm{SnS}_{2}$, showing the intrinsic metallic characteristic. The Fermi level is assigned at 0 eV

intensity varied from 0.45 to $1.05 \mathrm{~mW}$. A clear rise of the photocurrent with increasing illumination intensity was observed, indicating the effective conversion of photon flux to photogenerated carriers. In addition, the $\mathrm{Sn}_{0.5} \mathrm{~W}_{0.5} \mathrm{~S}_{2} / \mathrm{SnS}_{2}$ photodetector showed symmetric and linear $I-V$ plots, which is in sharp contrast to the non-linear $I-V$ curves observed for $\mathrm{SnS}_{2}$ based device (Supplementary Fig. 19a). This further indicates the low resistance contact formed between the semiconducting and metallic components in $\mathrm{Sn}_{0.5} \mathrm{~W}_{0.5} \mathrm{~S}_{2} / \mathrm{SnS}_{2}$. The temporal photoresponse of the photodetectors was measured as well as shown in Fig. 6b, c and Supplementary Figs. 19b, c. The $\mathrm{Sn}_{0.5} \mathrm{~W}_{0.5} \mathrm{~S}_{2} / \mathrm{SnS}_{2}$ photodetector showed an abrupt rise of photocurrent with a fast response time of $42.1 \mathrm{~ms}$ (defined as the time required to increase $90 \%$ from the minimum to maximum current density), which is comparable and outperforms some previously reported TMC based photodetectors ${ }^{58,59}$. This value is also about 50 times shorter than that of the $\mathrm{SnS}_{2}$-based photodetector (2.10 s) (Supplementary Fig. 19c). Such markedly shortened response time suggests the rapid transport of charge carriers across the $\mathrm{Sn}_{0.5} \mathrm{~W}_{0.5} \mathrm{~S}_{2} / \mathrm{SnS}_{2}$ heterointerfaces ${ }^{60,61}$. Note that a relatively large dark current and thus a much reduced on/off ratio were observed for the $\mathrm{Sn}_{0.5} \mathrm{~W}_{0.5} \mathrm{~S}_{2} / \mathrm{SnS}_{2}$-based device as compared with the $\mathrm{SnS}_{2}$ device. This was due to the metallic nature of the $\mathrm{Sn}_{0.5} \mathrm{~W}_{0.5} \mathrm{~S}_{2}$ nanosheets. The similar phenomenon was reported previously in photodetectors based on graphene composites ${ }^{62,63}$.
$\mathrm{Sn}_{\mathbf{0 . 5}} \mathrm{W}_{0.5} \mathrm{~S}_{2} / \mathrm{SnS}_{2}$ for gas sensing. The presence of a metallic component in a thin film channel may pose some limitation to its optoelectronic performance, such as the relatively large dark current observed in the aforementioned $\mathrm{Sn}_{0.5} \mathrm{~W}_{0.5} \mathrm{~S}_{2} / \mathrm{SnS}_{2}$ photodetector. However, the metallic structure might become an advantage for applications like sensors. As another proof of concept demonstration of the advantage of solution-processible functional materials, the $\mathrm{Sn}_{0.5} \mathrm{~W}_{0.5} \mathrm{~S}_{2} / \mathrm{SnS}_{2}$ heterostructures were deposited on $\mathrm{Au}$ interdigitated electrodes to fabricate chemiresistive gas sensors for detection of volatile organic compounds such as acetone, which is a potential biomarker for diabetes and lung cancer ${ }^{64}$. For comparison, $\mathrm{SnS}_{2}$-based gas sensors were also fabricated. The response-recovery curves of the gas sensors were measured under gas flows with increasing concentrations (typically $0.1-50 \mathrm{ppm}$ ) at room temperature (Fig. 7a, b and Supplementary Figs. 20 and 21). Taking sensing of acetone for example, the resistance of the $\mathrm{Sn}_{0.5} \mathrm{~W}_{0.5} \mathrm{~S}_{2} / \mathrm{SnS}_{2}$ sensor decreased upon exposure to acetone and the decrease in resistance $\left(\Delta R=R_{\mathrm{a}}-R_{0}\right)$ with increasing acetone concentration (Fig. 7a, b and Supplementary Fig. 20). A minimum detectable concentration of 0.1 ppm was achieved. This is 20 times lower compared to that of the sensor based on $\mathrm{SnS}_{2}$ which only afforded a minimum detectable concentration of 2 ppm (Supplementary Fig. 21), and to the best of our knowledge, outperforms other reported metal sulfide/oxide chemiresistive acetone sensors. More importantly, our sensor 

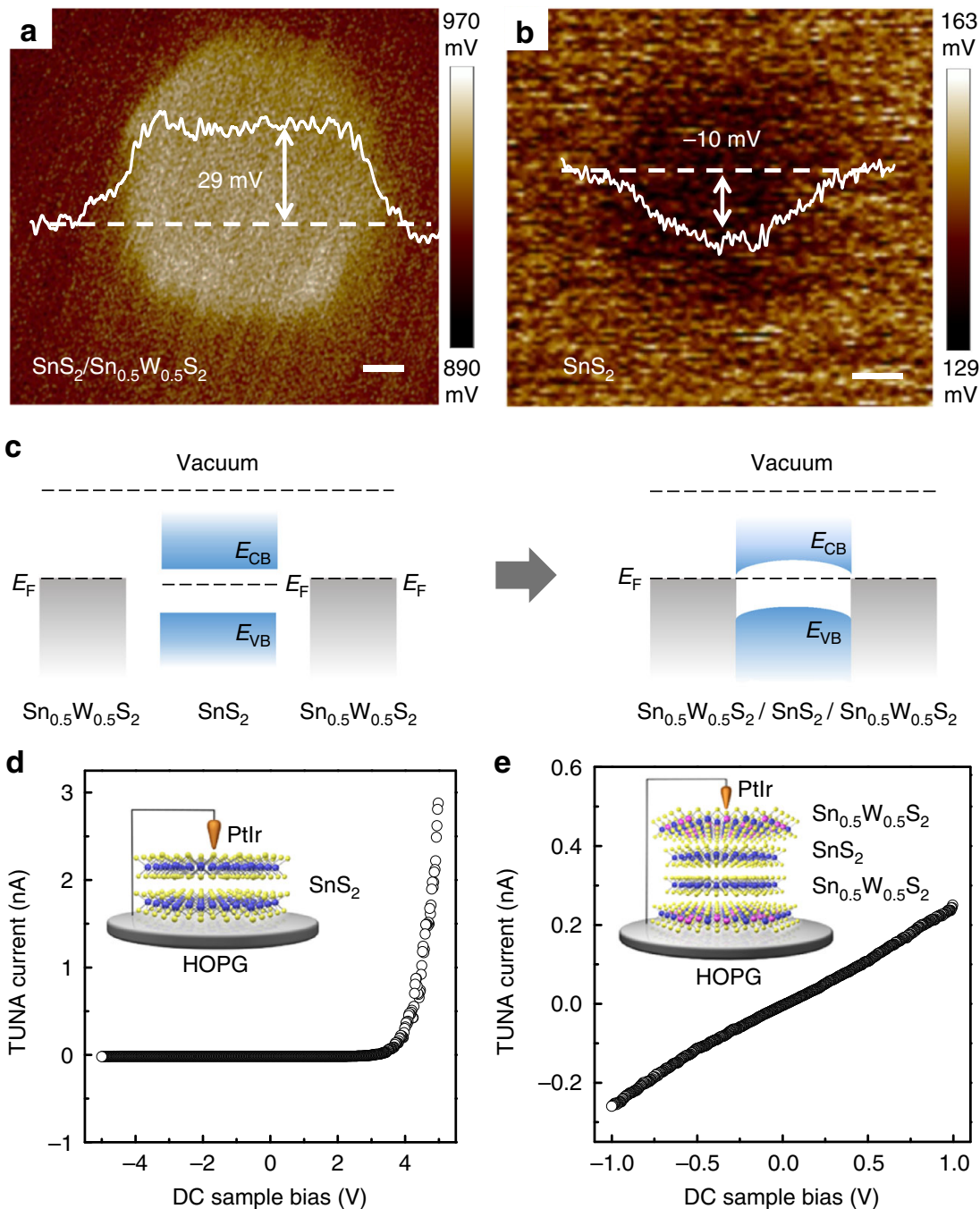

Fig. $5 \mathrm{KPFM}$ and TUNA analyses of $\mathrm{SnS}_{2}$ and $\mathrm{Sn}_{0.5} \mathrm{~W}_{0.5} \mathrm{~S}_{2} / \mathrm{SnS}_{2}$ heterostructures. 2D potential images of a typical $\mathrm{Sn}_{0.5} \mathrm{~W}_{0.5} \mathrm{~S}_{2} / \mathrm{SnS}_{2}$ heterostructure (scale bar, $200 \mathrm{~nm}$ ) and $\mathbf{b}$ a typical $\mathrm{SnS}_{2}$ nanoplate deposited on a $\mathrm{SiO}_{2} / \mathrm{Si}$ substrate coated with a thin film of $\mathrm{Au} / \mathrm{Cr}$ (i.e., $\mathrm{Au} / \mathrm{Cr} / \mathrm{SiO} 2 / \mathrm{Si}$ ) (scale bar, $100 \mathrm{~nm}$ ). c Schematic band alignment diagram for $\mathrm{Sn}_{0.5} \mathrm{~W}_{0.5} \mathrm{~S}_{2}$ and $\mathrm{SnS}_{2}$ before and after contact. $E_{\mathrm{F}}, E_{\mathrm{CB}}$, and $E_{\mathrm{VB}}$ denote Fermi level, conduction band and valence band, respectively. I-V curves measured with TUNA for $\mathbf{d}$ a $\mathrm{SnS}_{2}$ nanoplate and e a $\mathrm{Sn}_{0.5} \mathrm{~W}_{0.5} \mathrm{~S}_{2} / \mathrm{SnS}_{2}$ heterostructure, under a constant force and an applied bias voltage that was linearly ramped down
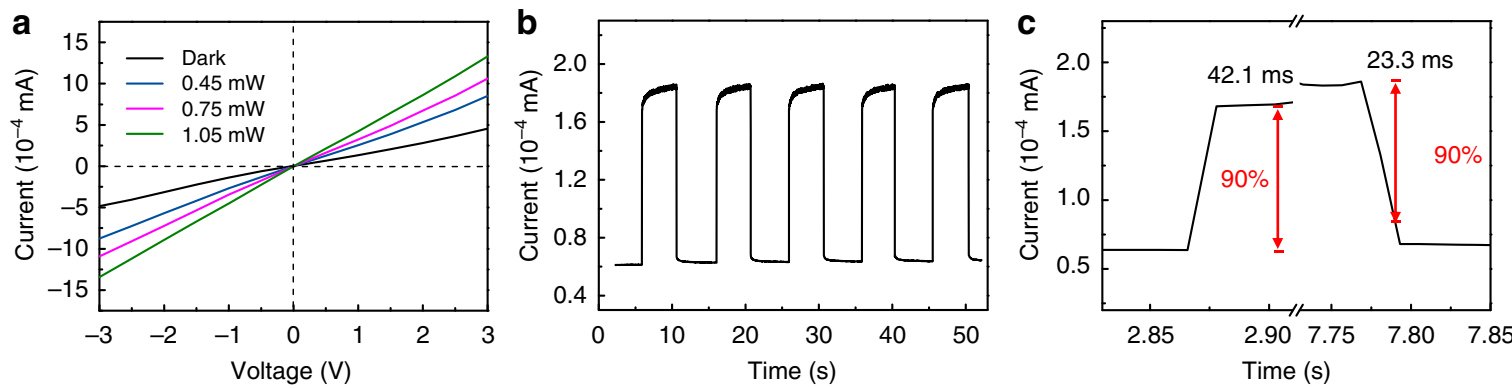

Fig. 6 Photodetector performance of $\mathrm{Sn}_{0.5} \mathrm{~W}_{0.5} \mathrm{~S}_{2} / \mathrm{SnS}_{2}$ heterostructures. a $\mathrm{l}-\mathrm{V}$ curves at different light intensity, b temporal photocurrent response and $\mathbf{c}$ a zoom-in view of the temporal photocurrent response of a photodetector based on $\mathrm{Sn}_{0.5} \mathrm{~W}_{0.5} \mathrm{~S}_{2} / \mathrm{SnS}_{2}$ heterostructures. The light source used for all measurements was a $405 \mathrm{~nm}$ laser

showed the best sensitivity (i.e., sensing response, $\Delta R / R_{0}$ ) at 100 ppb levels among all reported chemiresistive sensors operating at room temperature (Supplementary Table 3). Furthermore, as shown in Supplementary Fig. 22, a typical $\mathrm{Sn}_{0.5} \mathrm{~W}_{0.5} \mathrm{~S}_{2} / \mathrm{SnS}_{2}$ sensor was repeatedly exposed to $1 \mathrm{ppm}$ acetone and then back to $\mathrm{N}_{2}$ gas for 10 cycles and showed an almost constant sensing response of $1.88 \pm 0.07 \%$ (by taking standard deviation of the results from 10 cycles), indicating its good repeatability. 


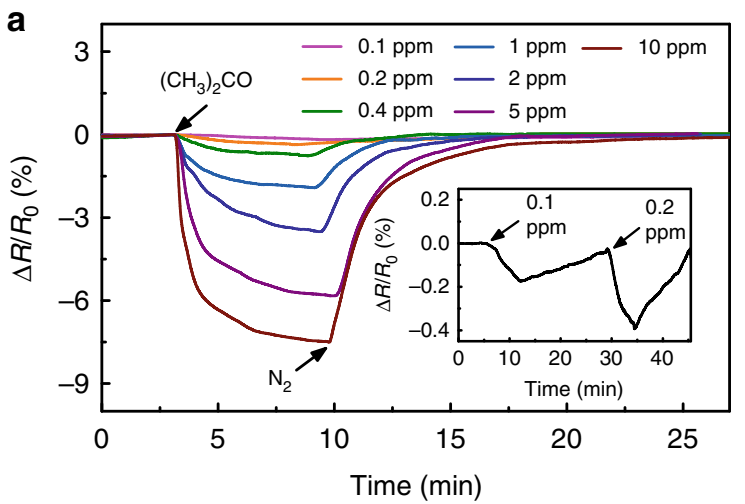

C

\begin{tabular}{cc}
\hline Material & $E_{\mathrm{a}}(\mathrm{eV})$ \\
\hline $\mathrm{SnS}_{2}$ & 0.40 \\
$\mathrm{Sn}_{0.5} \mathrm{~W}_{0.5} \mathrm{~S}_{2}$ & 2.37 \\
$\mathrm{NH}_{4}^{+}$-intercalated \\
$\mathrm{Sn}_{0.5} \mathrm{~W}_{0.5} \mathrm{~S}_{2}$
\end{tabular}

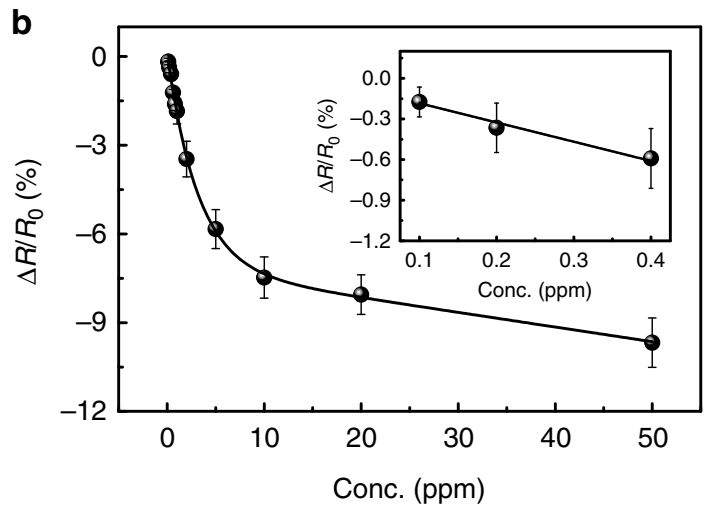

$\mathbf{e}$

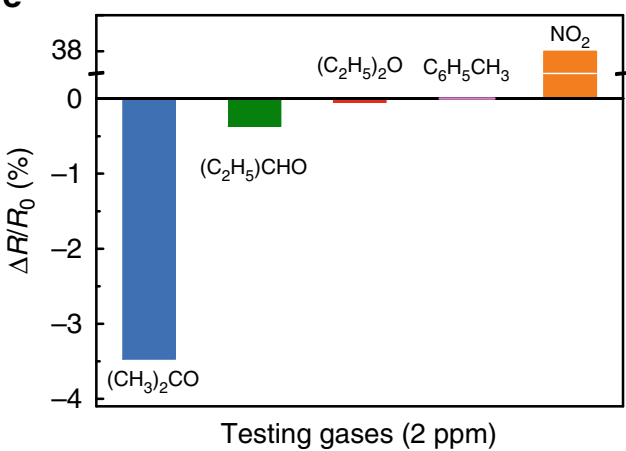

Fig. 7 Gas sensing performance of $\mathrm{Sn}_{0.5} \mathrm{~W}_{0.5} \mathrm{~S}_{2} / \mathrm{SnS}_{2}$ heterostructures. a Response-recovery curves of a typical chemiresistive sensor fabricated from $\mathrm{Sn}_{0.5} \mathrm{~W}_{0.5} \mathrm{~S}_{2} / \mathrm{SnS}_{2}$ heterostructures in response to acetone gas with increasing concentrations. Inset: zoom-in response of the sensor towards 0.1 and 0.2 ppm acetone. $\mathbf{b}$ Normalized change of resistance of $\mathrm{Sn}_{0.5} \mathrm{~W}_{0.5} \mathrm{~S}_{2} / \mathrm{SnS}_{2}$ sensors at various acetone concentrations. Inset: zoom-in normalized change of resistance at low acetone concentrations. Each error bar indicates the standard deviation of the change of resistance for 5 experimental replicates. c Calculated adsorption energy, $E_{\mathrm{a}}(\mathrm{eV})$, of acetone on different sensing materials. $\mathbf{d}$ Side view of the fully relaxed structural model of $\mathrm{Sn}_{0.5} \mathrm{~W}_{0.5} \mathrm{~S}_{2}$ with surface adsorption of an acetone molecule. Cyan regions indicate charge accumulation, while pink regions represent charge depletion. $\mathbf{e}$ Comparison of the responses of the sensor towards different gases, including acetone, diethyl ether, propanal, toluene, and $\mathrm{NO}_{2}$

The improved sensitivity after deposition of $\mathrm{Sn}_{0.5} \mathrm{~W}_{0.5} \mathrm{~S}_{2}$ nanosheets on $\mathrm{SnS}_{2}$ nanoplates could be attributed to the following reasons. First, the formation of an ohmic-like contact between $\mathrm{Sn}_{0.5} \mathrm{~W}_{0.5} \mathrm{~S}_{2}$ and $\mathrm{SnS}_{2}$ that allowed rapid charge transfer across the metal-semiconductor interface partly led to a 35 times reduction in background noise and thus a much higher signal to noise $(\mathrm{S} / \mathrm{N})$ ratio (Supplementary Fig. 23) ${ }^{27}$. Second, it can be noted that, the response/recovery time of the $\mathrm{Sn}_{0.5} \mathrm{~W}_{0.5} \mathrm{~S}_{2} / \mathrm{SnS}_{2}$ gas sensor was longer than that of the $\mathrm{SnS}_{2}$ gas sensor (Fig. $7 \mathrm{a}$ and Supplementary Fig. 21), pointing to a chemical adsorption-related sensing pathway ${ }^{64,65}$. To confirm this, we calculated the adsorption energy of acetone on the different sensing materials (Fig. 7c). The adsorption energy of acetone on $\mathrm{Sn}_{0.5} \mathrm{~W}_{0.5} \mathrm{~S}_{2}$ is 2.37 $\mathrm{eV}$ is much larger compared to that on $\mathrm{SnS}_{2}(0.40 \mathrm{eV})$. This indicates that acetone molecules interact more strongly with $\mathrm{Sn}_{0.5} \mathrm{~W}_{0.5} \mathrm{~S}_{2}$. It is worth noting that the $\mathrm{NH}_{4}{ }^{+}$-intercalation did not significantly change the adsorption ability of $\mathrm{Sn}_{0.5} \mathrm{~W}_{0.5} \mathrm{~S}_{2}$ nanosheets towards acetone, with the adsorption energy slightly reduced by $0.09 \mathrm{eV}$. As further shown in Fig. $7 \mathrm{~d}$, there is an obvious charge accumulation on $\mathrm{Sn}_{0.5} \mathrm{~W}_{0.5} \mathrm{~S}_{2}$ due to charge transfer from the absorbed acetone molecule. Third, one of the advantages of using low-dimensional materials in gas sensing as compared with bulk crystals is their large specific surface areas, which are beneficial for providing large interfaces for channel-gas interaction ${ }^{25}$. Indeed, the deposition of wrinkled $\mathrm{Sn}_{0.5} \mathrm{~W}_{0.5} \mathrm{~S}_{2}$ nanosheets on $\mathrm{SnS}_{2}$ nanoplates increased the specific surface areas from typically 6.25 to $11.37 \mathrm{~m}^{2} / \mathrm{g}$ based on the Brunauer-Emmett-Teller (BET) measurements as shown in
Supplementary Fig. 24. However, in spite of the beneficial effects from the large specific surface area of the wrinkled $\mathrm{Sn}_{0.5} \mathrm{~W}_{0.5} \mathrm{~S}_{2}$ nanosheets and their strong interaction with acetone, increasing the amount of $\mathrm{Sn}_{0.5} \mathrm{~W}_{0.5} \mathrm{~S}_{2}$ nanosheets on $\mathrm{SnS}_{2}$ did not further improve the sensing performance, but on the contrary, led to poorer sensitivity with a minimal detectable concentration of only $1 \mathrm{ppm}$ (Supplementary Fig. 25). This suggests that the concentration of the metallic phase present in the hybrid sensing film should not be too high, otherwise, the gas-induced doping effect on the semiconducting $\mathrm{SnS}_{2}$ would be substantially weakened. Therefore, the presence of the semiconductor/metal heterostructures with a low charge transfer barrier, combined with sufficient active surfaces for strong gas adsorption are important in achieving low sensitivity in our thin film based gas sensors.

The selectivity of the $\mathrm{Sn}_{0.5} \mathrm{~W}_{0.5} \mathrm{~S}_{2} / \mathrm{SnS}_{2}$ sensor was also investigated by comparing its sensing response towards acetone with other electron donating gases like diethyl ether and propanal, neutral gas like toluene, and electron withdrawing gas like $\mathrm{NO}_{2}$ (Fig. 7e, Supplementary Fig. 26). The response of the $\mathrm{Sn}_{0.5} \mathrm{~W}_{0.5} \mathrm{~S}_{2} / \mathrm{SnS}_{2}$ sensor towards diethyl ether and propanal was 10 times lower compared to that towards acetone at $2 \mathrm{ppm}$. This is largely due to the weaker electron donating ability of diethyl ether and propanal compared to that of acetone (Fig. 7e). Under the exposure of toluene, the sensor showed no response. In sharp contrast, when responding to $\mathrm{NO}_{2}$, an electron withdrawing gas, the sensor showed increased resistance (Fig. 7e, Supplementary Fig. 26e), agreeing with the fact that $\mathrm{SnS}_{2}$ is an n-type semiconductor (Supplementary Fig. 18b). 


\section{Discussion}

The epitaxial growth of metallic $\mathrm{Sn}_{0.5} \mathrm{~W}_{0.5} \mathrm{~S}_{2}$ nanosheets on the surfaces of $\mathrm{SnS}_{2}$ nanoplates were realized via a solution-phase epitaxial deposition process. Importantly, an alloyed metal oxide (i.e., $\mathrm{Sn}_{0.17} \mathrm{WO}_{3}$ ) was identified as an intermediate product which formed at $180^{\circ} \mathrm{C}$ and decomposed subsequently at $220^{\circ} \mathrm{C}$ to provide additional $\mathrm{Sn}$ and $\mathrm{W}$ ions with a high $\mathrm{W} / \mathrm{Sn}$ ratio of about 30 . We proposed that this high W/Sn concentration could drive the formation of alloyed $\mathrm{Sn}_{0.5} \mathrm{~W}_{0.5} \mathrm{~S}_{2}$ nanosheets despite the fact that the formation of $\mathrm{Sn}-\mathrm{S}$ bond requires less energy compared to that of the W-S bond. Although $1 \mathrm{~T}-\mathrm{SnS}_{2}$ is a semiconductor, alloyed $\mathrm{Sn}_{0.5} \mathrm{~W}_{0.5} \mathrm{~S}_{2}$ showed $83 \%$ distorted $1 \mathrm{~T}$ structure, which is metal-like as predicted by theoretical calculations. KPFM and TUNA measurements on a $\mathrm{Sn}_{0.5} \mathrm{~W}_{0.5} \mathrm{~S}_{2} / \mathrm{SnS}_{2}$ heterostructure suggested the formation of ohmic-like contact at the heterointerface, resulting in a low charge transfer resistance. The rapid charge transport at the $\mathrm{Sn}_{0.5} \mathrm{~W}_{0.5} \mathrm{~S}_{2} / \mathrm{SnS}_{2}$ heterointerface allowed for the fabrication of fast photodetector with a short response time of $42 \mathrm{~ms}$. Additionally, when the $\mathrm{Sn}_{0.5} \mathrm{~W}_{0.5} \mathrm{~S}_{2} / \mathrm{SnS}_{2}$ heterostructures were fabricated into thin films for gas sensing, a much enhanced signal-to-noise ratio was achieved partly due to the presence of metallic $\mathrm{Sn}_{0.5} \mathrm{~W}_{0.5} \mathrm{~S}_{2}$ layers. Furthermore, $\mathrm{Sn}_{0.5} \mathrm{~W}_{0.5} \mathrm{~S}_{2}$ showed much enhanced surface adsorption of acetone than $\mathrm{SnS}_{2}$ based on theoretical calculations. As a consequence, selective and sensitive detection of acetone was achieved with an ultralow minimum detectable concentration of $100 \mathrm{ppb}$ at room temperature. This, combined with large sensing responses at $100 \mathrm{ppb}$ levels outperforms previously reported room-temperature chemiresistive sensors. Our use of semiconducting $\mathrm{SnS}_{2}$ nanoplates as synthesis templates for the solution-phase epitaxial growth of metallic $\mathrm{Sn}_{0.5} \mathrm{~W}_{0.5} \mathrm{~S}_{2}$ nanosheets demonstrates a promising way towards the facile, economic and high-yield preparation of functional hybrid nanomaterials. Synthesis of layered materials through alloying among elements with distinct electronic and chemical properties is expected to bring about more materials and unusual phenomena.

\section{Methods \\ Materials. Ammonium tungstate hydrate $\left(\left(\mathrm{NH}_{4}\right)_{10} \mathrm{H}_{2}\left(\mathrm{~W}_{2} \mathrm{O}_{7}\right)_{6}, 99.99 \%\right)$, ammo- nium molybdate tetrahydrate $\left(\left(\mathrm{NH}_{4}\right)_{6} \mathrm{Mo}_{7} \mathrm{O}_{24} \cdot 4 \mathrm{H}_{2} \mathrm{O}, 99.0 \%\right)$, thiourea $\left(\mathrm{CS}\left(\mathrm{NH}_{2}\right)_{2}\right.$, 99.0\%) and tin tetrachloride hydrate $\left(\mathrm{SnCl}_{4} \cdot 5 \mathrm{H}_{2} \mathrm{O}, 99.9 \%\right)$ were purchased from Sigma-Aldrich (Shanghai, China). Ethanol $\left(\mathrm{C}_{2} \mathrm{H}_{5} \mathrm{OH}\right.$, ACS, 99.9\%) was purchased from J\&K chemical (Shanghai, China). The gaseous analytes $\left(\mathrm{CH}_{3} \mathrm{COCH}_{3}\right.$, $\left(\mathrm{CH}_{3} \mathrm{CH}_{2}\right)_{2} \mathrm{O}, \mathrm{CH}_{3} \mathrm{CH}_{2} \mathrm{CHO}, \mathrm{C}_{6} \mathrm{H}_{5} \mathrm{CH}_{3}$, and $\left.\mathrm{NO}_{2}\right)$ which were diluted with $\mathrm{N}_{2}$ gas at concentrations of $1000 \mathrm{ppm}$ were purchased from Nanjing Teqi Co., Ltd. All chemicals were used as received without further purification. The deionized (DI) water was purified using Milli-Q3 System (Millipore, France).}

Preparation of $\mathbf{S n S}_{\mathbf{2}}$ nanoplates. In a typical process, $0.25 \mathrm{mmol}$ of $\mathrm{SnCl}_{4} \cdot 5 \mathrm{H}_{2} \mathrm{O}$ and $3.75 \mathrm{mmol}$ of $\mathrm{CS}\left(\mathrm{NH}_{2}\right)_{2}$ were dissolved in $19.45 \mathrm{~mL}$ DI water and stirred for 2 $\mathrm{h}$ to form a homogeneous solution. This solution was transferred to a $25 \mathrm{~mL}$ Teflon-lined stainless steel autoclave, heated to $220^{\circ} \mathrm{C}$ in an electrical oven and then maintained at this temperature for $12 \mathrm{~h}$ before being cooled down naturally to room temperature. The obtained product was centrifuged at $8000 \mathrm{rpm}$ for $10 \mathrm{~min}$, and the precipitate was washed with DI water for three times before further characterization.

Preparation of $\mathbf{S n}_{\mathbf{0 . 5}} \mathbf{W}_{\mathbf{0 . 5}} \mathbf{S}_{\mathbf{2}} / \mathbf{S n S} \mathbf{S}_{\mathbf{2}}$ heterostructures. In a typical process, 0.25 $\mathrm{mmol}$ of $\left(\mathrm{NH}_{4}\right)_{10} \mathrm{H}_{2}\left(\mathrm{~W}_{2} \mathrm{O}_{7}\right)_{6}, 7.5 \mathrm{mmol}$ of $\mathrm{CS}\left(\mathrm{NH}_{2}\right)_{2}$, and $0.5-0.625 \mathrm{mmol}$ of $\mathrm{SnCl}_{4} \cdot 5 \mathrm{H}_{2} \mathrm{O}$ were dissolved in $19.45 \mathrm{~mL}$ DI water and stirred at $80^{\circ} \mathrm{C}$ for $2 \mathrm{~h}$ to form a homogeneous solution. This solution was then transferred to a $25 \mathrm{~mL}$ Teflon-lined stainless steel autoclave, heated to $220^{\circ} \mathrm{C}$ in an electrical oven and then maintained at this temperature for $60 \mathrm{~h}$ before being cooled down naturally to room temperature. The obtained product was centrifuged at $8000 \mathrm{rpm}$ for $10 \mathrm{~min}$, and the precipitate was washed with DI water for three times before further characterization.

Characterizations. Scanning electron microscope (SEM, JEOL JSM-7800F, Japan), transmission electron microscope (TEM, JEOL 2100Plus, Japan) and high resolution transmission electron microscope (HRTEM, JEOL 2100 F, Japan) coupled with energy dispersive X-ray (EDX) spectroscope were used to investigate the compositional, morphological and structural features of the samples. X-ray diffraction (XRD, Rigaku SmartLab, Japan) was performed using CuKa radiation $(\lambda=1.54 \AA$ ). X-ray photoelectron spectroscopy (XPS, PHI 5000 VersaProbe, Japan) measurements were conducted on the different metal sulfide nanostructures, and the binding energies were corrected for specimen charging effects using the $\mathrm{C} 1 \mathrm{~s}$ level at $284.6 \mathrm{eV}$ as the reference. Raman spectra (Horiba HR800, France) of the samples were collected with a $532 \mathrm{~nm}$ laser. Semiconductor parameter analyzer (Tektronix Keithley 4200, America) and probe station (Lake Shore TTPX, America) were used to investigate the semiconductor properties of the samples. A commercial atomic force microscope (AFM, Dimension ICON with Nanoscope V controller, Bruker) was used to investigate the electrical properties of the individual nanostructures in air. Inductively coupled plasma mass spectrometry (ICP-MS, Agilent $7700 \times$, America) was used to measure the concentration of $\mathrm{Sn}$ and $\mathrm{W}$ ions in the synthesis solution. Brunauer-Emmett-Teller (BET, Micromeritics, ASAP2460, USA) measurements were carried out to determine the specific surface area and pore size distribution of various samples.

Semiconducting property characterization. After $\mathrm{Au}(50 \mathrm{~nm}) / \mathrm{Cr}(30 \mathrm{~nm}) \mathrm{drain}$ and source electrodes were deposited onto $\mathrm{S} \mathrm{SiO}_{2}(285 \mathrm{~nm}) / \mathrm{Si}$ substrate via therma evaporation through a shadow mask, $\mathrm{SnS}_{2}$ nanoplates or $\mathrm{Sn}_{0.5} \mathrm{~W}_{0.5} \mathrm{~S}_{2} / \mathrm{SnS}_{2}$ heterostructures in water were drop-casted onto the substrate, acting as the channel to connect the drain and source electrodes with a channel length of $11 \mu \mathrm{m}$. The semiconducting properties of the channel materials were then characterized using a Keithley 4200 semiconductor characterization system operating at $77 \mathrm{~K}$ in vacuum $\left(5 \times 10^{-5}\right.$ Torr $)$

KPFM and TUNA measurements. After $\mathrm{Au}(50 \mathrm{~nm}) / \mathrm{Cr}(30 \mathrm{~nm})$ was coated onto a $\mathrm{SiO}_{2}(285 \mathrm{~nm}) / \mathrm{Si}$ substrate via thermal evaporation, $\mathrm{SnS}_{2}$ nanoplates (or $\mathrm{Sn}_{0.5} \mathrm{~W}_{0.5} \mathrm{~S}_{2} / \mathrm{SnS}_{2}$ heterostructures) in water were drop-casted onto the substrate. A KPFM (Dimension ICON with Nanoscope V controller, Bruker) was then used to characterize the surface potential of the $\mathrm{SnS}_{2}$ nanoplates (or $\mathrm{Sn}_{0.5} \mathrm{~W}_{0.5} \mathrm{~S}_{2} / \mathrm{SnS}_{2}$ heterostructures) at ambient conditions. The contact potential difference between the tip (PtIr) and the sample surface $\left(V_{\mathrm{CPD}}\right)$, which is also referred to as the surface potential can be calculated by using the following equations:

$$
\begin{gathered}
V_{\mathrm{CPD}}=\frac{1}{e}\left(\varphi_{\mathrm{t}}-\varphi_{\mathrm{f}}\right) \\
\Delta V_{\mathrm{CPD}}=\Delta V_{\mathrm{CPD}}(\text { film })-\Delta V_{\mathrm{CPD}}(\text { substrate }) \\
\Delta V_{\mathrm{CPD}}=\frac{1}{e}\left(\varphi_{\mathrm{t}}-\varphi_{\mathrm{f}}\right)-\frac{1}{e}\left(\varphi_{\mathrm{t}}-\varphi_{\mathrm{s}}\right)=\frac{1}{e}\left(\varphi_{\mathrm{s}}-\varphi_{\mathrm{f}}\right)
\end{gathered}
$$

where $\varphi_{\mathrm{t}}, \varphi_{\mathrm{s}}$, and $\varphi_{\mathrm{f}}$ represent the work functions of the probe tip, the substrate, and the sample film, respectively.

PeakForce Tunneling atomic force microscopy (TUNA, Dimension ICON with Nanoscope V controller, Bruker) was used to investigate the current-voltage $(I-V)$ characteristics of individual $\mathrm{SnS}_{2}$ nanoplates or $\mathrm{Sn}_{0.5} \mathrm{~W}_{0.5} \mathrm{~S}_{2} / \mathrm{SnS}_{2}$ heterostructures. During the measurement, the PtIr tip was pressed against the sample with a constant force, feedback was switched to contact mode, and the voltage was linearly ramped up and down while the current signal was collected. Analysis of the $I-V$ curves was performed with the Nanoscope Analysis software.

Fabrication of photodetector and photoresponse measurements. Au (15 nm in thickness) interdigitated electrodes with a $10 \mathrm{~nm}$ spacing were deposited onto a $\mathrm{SiO}_{2}(300 \mathrm{~nm}) / \mathrm{Si}$ substrate via magnetron sputtering through a shadow mask. After that, $0.5 \mu \mathrm{L}$ of a concentrated dispersion $(6.0 \mathrm{mg} / \mathrm{mL})$ of the $\mathrm{Sn}_{0.5} \mathrm{~W}_{0.5} \mathrm{~S}_{2} / \mathrm{SnS}_{2}$ heterostructures or $\mathrm{SnS}_{2}$ nanoplates was drop-casted on the electrodes.

The current-voltage $(I-V)$ and the current-time $(I-t)$ curves of the photodetectors were measured on a semiconductor characterization system (Keithley 4200, USA) in air at room temperature. A $405 \mathrm{~nm}$ laser was used for all the measurements. The actual power intensity was measured by a power meter (LP1, Sanwa Electric Instrument Co., Ltd., Japan).

Fabrication of chemiresistive sensors and gas sensing tests. Chemiresistive gas sensors were fabricated based on $\mathrm{SnS}_{2}$ nanoplates or $\mathrm{Sn}_{0.5} \mathrm{~W}_{0.5} \mathrm{~S}_{2} / \mathrm{SnS}_{2}$ heterostructures for sensing of various gases, including $\mathrm{CH}_{3} \mathrm{COCH}_{3},\left(\mathrm{CH}_{3} \mathrm{CH}_{2}\right)_{2} \mathrm{O}$, $\mathrm{CH}_{3} \mathrm{CH}_{2} \mathrm{CHO}, \mathrm{C}_{6} \mathrm{H}_{5} \mathrm{CH}_{3}$, and $\mathrm{NO}_{2}$. Typically, a drop of $100 \mu \mathrm{L}$ aqueous solution containing $10 \mathrm{mM}$ as-prepared $\mathrm{SnS}_{2}$ or $\mathrm{Sn}_{0.5} \mathrm{~W}_{0.5} \mathrm{~S}_{2} / \mathrm{SnS}_{2}$ was drop-casted onto an $\mathrm{Au}$ interdigitated electrode (with $0.1 \mathrm{~mm}$ spacing over a $2 \times 1 \mathrm{~cm}^{2}$ area, Changchun Mega Borui Technology Co., Ltd) and then dried in oven at $60^{\circ} \mathrm{C}$. The gas sensing test was performed in an air-tight chamber with electrical feedthroughs at room temperature $\left(25^{\circ} \mathrm{C}\right)$. A constant current was applied to the sensor electrode, and the variation of the sensor resistance was monitored and recorded with the changes in the gas environment using a data acquisition system (34972A, Agilent) with a 20 channel multiplexer (34901A, Agilent). A typical sensing measurement cycle consisted of three sequential steps: (1) a dried $\mathrm{N}_{2}$ flow was introduced into the chamber to record a baseline resistance $\left(R_{0}\right) ;(2)$ a target gas, e.g., acetone, balanced in $\mathrm{N}_{2}$ was introduced, and the concentration increased $(0.1-50 \mathrm{ppm})$ with 
progressive cycles; and (3) when the resistance of the sensor reached equilibrium in the target gas $\left(R_{\mathrm{a}}\right)$, the target gas was replaced by $\mathrm{N}_{2}$ to allow the resistance of the sensor to return to $R_{0}$. All gas flows were set at $500 \mathrm{sccm}$, precisely controlled by using mass-flow controllers.

Computational methods. All the computations were performed with Vienna Ab initio simulation package (VASP) which is based on the density functional theory $(\mathrm{DFT})^{66,67}$. The exchange-correlation interaction uses the general gradient approximation (GGA) formulated by Perdew-Burke-Ernzerhof $(\mathrm{PBE})^{66}$. All electron interactions were described with projector augmented wave (PAW) pseudo potentials. Long-range dispersion corrections have been considered within the DFT-D2 method. The dispersion coefficient $\mathrm{C}_{6}$ and van der Waals radius $R_{0}$ for $\mathrm{H}, \mathrm{C}, \mathrm{N}, \mathrm{O}, \mathrm{S}, \mathrm{Sn}$ and $\mathrm{W}$ used in our DFT-D2 method were taken from previous reports ${ }^{68,69}$. The scale factor $S_{6}$ was set to 0.75 because the GGA-PBE function was employed. An $11 \times 11 \times 1 \mathrm{k}$-point mesh was used for the interaction of the Brillouin-zone. The cutoff energy for the plane wave basis set was restricted to 400 $\mathrm{eV}$, and a vacuum region of at least $12 \AA$ was used in building the slab models. The convergence threshold was set as $10^{-4} \mathrm{eV}$ in energy and $0.02 \mathrm{eV} / \AA$ in force, respectively. As shown in Fig. $4 c$, a four-layer $1 \mathrm{~T}-\mathrm{Sn}_{0.5} \mathrm{~W}_{0.5} \mathrm{~S}_{2}$ on a monolayer $1 \mathrm{~T}$ $\mathrm{SnS}_{2}$ was constructed with a $2 \times 2$ supercell, which contains $24 \mathrm{Sn}, 16 \mathrm{~W}$ and $80 \mathrm{~S}$ atoms, respectively. Three $\mathrm{NH}_{4}{ }^{+}$ions were introduced in the four-layer 1T$\mathrm{Sn}_{0.5} \mathrm{~W}_{0.5} \mathrm{~S}_{2}$ on a monolayer $1 \mathrm{~T}-\mathrm{SnS}_{2}$ system (Supplementary Fig. 10). All atoms in the structure were fully relaxed to optimize without any restriction, and the convergence threshold was set as $10^{-4} \mathrm{eV}$ in energy and $0.02 \mathrm{eV} / \AA$ in force, respectively. The optimized lattice constants and work functions $(\Phi)$ were summarized in Supplementary Table 1 . The experimental lattice constant $(a=3.46 \AA)$ was used in DFT calculations for the in-plane periodicity of the four-layer $1 \mathrm{~T}-\mathrm{Sn}_{0.5} \mathrm{~W}_{0.5} \mathrm{~S}_{2}$ on a monolayer $1 \mathrm{~T}-\mathrm{SnS}_{2}$ without and with intercalated $\mathrm{NH}_{4}{ }^{+}$ions. To evaluate the stability of the adsorption of an acetone molecule on a three-layer 1T-SnS ${ }_{2}$ and three-layer $1 \mathrm{~T}-\mathrm{Sn}_{0.5} \mathrm{~W}_{0.5} \mathrm{~S}_{2}$ without and with intercalated $\mathrm{NH}_{4}{ }^{+}$ions (each system contains a $4 \times 4$ supercell), the adsorption was defined by $\triangle E_{\mathrm{a}=} E_{\text {acetone }}+E_{\text {sub- }}$ strate-Eacetone-substrate (where $E_{\text {acetone-substrate }}$ is the total energy of the acetone/ substrate compound systems, whereas $E_{\text {acetone }}$ and $E_{\text {substrate }}$ are the energy of the isolated acetone molecule, and the total energies of upper two-layer relaxed and bottom-layer fixed $1 \mathrm{~T}-\mathrm{SnS}_{2}$ or distorted $1 \mathrm{~T}-\mathrm{Sn}_{0.5} \mathrm{~W}_{0.5} \mathrm{~S}_{2}$ without or with intercalated $\mathrm{NH}_{4}{ }^{+}$ions systems, respectively. VESTA was used for preparation of the structure models ${ }^{70}$.

\section{Data availability}

The data that support the findings of this study are available from the corresponding author on request.

Received: 27 January 2018 Accepted: 1 August 2018

Published online: 06 September 2018

\section{References}

1. Liu, Y. et al. Van der Waals heterostructures and devices. Nat. Rev. Mater. 1, 16042-16058 (2016).

2. Cho, S. et al. Phase patterning for ohmic homojunction contact in $\mathrm{MoTe}_{2}$. Science 349, 625-628 (2015).

3. Gong, Y. et al. Vertical and in-plane heterostructures from $\mathrm{WS}_{2} / \mathrm{MoS}_{2}$ monolayers. Nat. Mater. 13, 1135-1142 (2014).

4. Chhowalla, M. et al. The chemistry of two-dimensional layered transition metal dichalcogenide nanosheets. Nat. Chem. 5, 263-275 (2013).

5. Loan, P. T. et al. Graphene/ $\mathrm{MoS}_{2}$ heterostructures for ultrasensitive detection of DNA hybridisation. Adv. Mater. 26, 4838-4844 (2014).

6. Chen, X. et al. High-quality sandwiched black phosphorus heterostructure and its quantum oscillations. Nat. Commun. 6, 7315 (2015).

7. Acerce, M., Voiry, D. \& Chhowalla, M. Metallic 1 T phase $\mathrm{MoS}_{2}$ nanosheets as supercapacitor electrode materials. Nat. Nanotechnol. 10, 313-318 (2015).

8. Song, S. et al. Room temperature semiconductor-metal transition of $\mathrm{MoTe}_{2}$ thin films engineered by strain. Nano Lett. 16, 188-193 (2016).

9. Rhodes, D. et al. Engineering the structural and electronic phases of $\mathrm{MoTe}_{2}$ through W substitution. Nano Lett. 17, 1616-1622 (2017).

10. Kappera, R. et al. Phase-engineered low-resistance contacts for ultrathin $\mathrm{MoS}_{2}$ transistors. Nat. Mater. 13, 1128-1134 (2014).

11. Yang, Z. et al. Wafer-scale synthesis of high-quality semiconducting twodimensional layered InSe with broadband photoresponse. ACS Nano 11, 4225-4236 (2017).

12. Ou, J. Z. et al. Physisorption-based charge transfer in two-dimensional $\mathrm{SnS}_{2}$ for selective and reversible $\mathrm{NO}_{2}$ gas sensing. ACS Nano 9, 10313-10323 (2015).

13. Bandurin, D. A. et al. High electron mobility, quantum Hall effect and anomalous optical response in atomically thin InSe. Nat. Nanotechol. 12, 223-227 (2017).
14. Huang, Y. et al. Tin disulfide-an emerging layered metal dichalcogenide semiconductor: materials properties and device characteristics. ACS Nano 8, 10743-10755 (2014).

15. $\mathrm{Hu}, \mathrm{X}$. et al. Phase-controlled synthesis and photocatalytic properties of $\mathrm{SnS}$, $\mathrm{SnS}_{2}$ and $\mathrm{SnS} / \mathrm{SnS}_{2}$ heterostructure nanocrystals. Mater. Res. Bull. 48, 2325-2332 (2013).

16. Nourbakhsh, A., Zubair, A., Dresselhaus, M. S. \& Palacios, T. Transport properties of a $\mathrm{MoS}_{2} / \mathrm{WSe}_{2}$ heterojunction transistor and its potential for application. Nano. Lett. 16, 1359-1366 (2016).

17. Cui, X. et al. Low-temperature ohmic contact to monolayer $\mathrm{MoS}_{2}$ by van der Waals bonded Co/h-BN electrodes. Nano Lett. 17, 4781-4786 (2017).

18. Tan, C., Chen, J., Wu, X.-J. \& Zhang, H. Epitaxial growth of hybrid nanostructures. Nat. Rev. Mater. 3, 17089 (2018).

19. Huang, X. et al. Solution-phase epitaxial growth of noble metal nanostructures on dispersible single-layer molybdenum disulfide nanosheets. Nat. Commun. 4, 1444 (2013).

20. Mudd, G. W. et al. High broad-band photoresponsivity of mechanically formed InSe-graphene van der Waals heterostructures. Adv. Mater. 27, 3760-3766 (2015)

21. Zhang, K. et al. Interlayer transition and infrared photodetection in atomically thin type-II $\mathrm{MoTe}_{2} / \mathrm{MoS}_{2}$ van der Waals heterostructures. ACS Nano 10, 3852-3858 (2016).

22. $\mathrm{Yu}, \mathrm{W}$. J. et al. Highly efficient gate-tunable photocurrent generation in vertical heterostructures of layered materials. Nat. Nanotechol. 8, 952-958 (2013).

23. Zhang, Z. et al. Unconventional solution-phase epitaxial growth of organic-inorganic hybrid perovskite nanocrystals on metal sulfide nanosheets. Sci. China Mater. https://doi.org/10.1007/s40843-018-9274-y (2018).

24. Konvalina, G. \& Haick, H. Sensors for breath testing: from nanomaterials to comprehensive disease detection. Acc. Chem. Res. 47, 66-76 (2014).

25. Kim, S. J., Choi, S. J., Jang, J. S., Cho, H. J. \& Kim, I. D. Innovative nanosensor for disease diagnosis. Acc. Chem. Res. 50, 1587-1596 (2017).

26. Kim, S. J. et al. Mesoporous $\mathrm{WO}_{3}$ nanofibers with protein-templated nanoscale catalysts for detection of trace biomarkers in exhaled breath. ACS Nano 10, 5891-5899 (2016).

27. Kim, S. J. et al. Metallic $\mathrm{Ti}_{3} \mathrm{C}_{2} \mathrm{~T}_{x}$ MXene gas sensors with ultrahigh signal-tonoise ratio. ACS Nano 12, 986-993 (2018).

28. Mayorga-Martinez, C. C., Ambrosi, A., Eng, A. Y. S., Sofer, Z. \& Pumera, M. Metallic $1 \mathrm{~T}-\mathrm{WS}_{2}$ for selective impedimetric vapor sensing. Adv. Funct. Mater. 25, 5611-5616 (2015)

29. Giberti, A. et al. Tin(IV) sulfide nanorods as a new gas sensing material. Sens Actuat. B Chem. 223, 827-833 (2016).

30. Kim, K. et al. Selective metal deposition at graphene line defects by atomic layer deposition. Nat. Commun. 5, 4781 (2014).

31. Wei, T.-Y., Yeh, P.-H., Lu, S.-Y. \& Wang, Z. L. Gigantic enhancement in sensitivity using schottky contacted nanowire nanosensor. J. Am. Chem. Soc. 131, 17690-17695 (2009).

32. Yang, K. et al. Composition- and phase-controlled synthesis and applications of alloyed phase heterostructures of transition metal disulphides. Nanoscale $\mathbf{9}$, 5102-5109 (2017).

33. Zhou, X., Zhang, Q., Gan, L., Li, H. \& Zhai, T. Large-size growth of ultrathin $\mathrm{SnS}_{2}$ nanosheets and high performance for phototransistors. Adv. Funct. Mater. 26, 4405-4413 (2016).

34. Shown, I. et al. Carbon-doped $\mathrm{SnS}_{2}$ nanostructure as a high-efficiency solar fuel catalyst under visible light. Nat. Commun. 9, 169 (2018).

35. Liu, Q. et al. Stable metallic 1T-WS 2 nanoribbons intercalated with ammonia ions: the correlation between structure and electrical/optical properties. Adv. Mater. 27, 4837-4844 (2015).

36. $\mathrm{Li}, \mathrm{X}$. et al. Van der Waals epitaxial growth of two-dimensional singlecrystalline GaSe domains on graphene. ACS Nano 9, 8078-8088 (2015)

37. Zhang, X. et al. Vertical heterostructures of layered metal chalcogenides by van der Waals epitaxy. Nano Lett. 14, 3047-3054 (2014).

38. Liao, Y. L., Cao, W., Connell, J. W., Chen, Z. F. \& Lin, Y. Evolution of moire profiles from van der Waals superstructures of boron nitride nanosheets. Sci. Rep. 6, 26084-26093 (2016).

39. Eda, G. et al. Coherent atomic and electronic heterostructures of single-layer $\mathrm{MoS}_{2}$. ACS Nano 6, 7311-7317 (2012).

40. Chen, P. et al. Large quantum-spin-Hall gap in single-layer $1 \mathrm{~T}^{\prime} \mathrm{WSe}_{2}$. Nat. Commun. 9, 2003 (2018).

41. Fei, Z. et al. Edge conduction in monolayer WTe $\mathrm{W}_{2}$. Nat. Phy. 13, 677-682 (2017).

42. Papageorgopoulos, C. A. \& Jaegermann, W. Li intercalation across and along the van der Waals surfaces of $\mathrm{MoS}_{2}$ (0001). Surf. Sci. 338, 83-93 (1995).

43. Voiry, D., Mohite, A. \& Chhowalla, M. Phase engineering of transition metal dichalcogenides. Chem. Soc. Rev. 44, 2702-2712 (2015).

44. Zhang, Z. et al. Hierarchical assembly of ultrathin hexagonal $\mathrm{SnS}_{2}$ nanosheets onto electrospun $\mathrm{TiO}_{2}$ nanofibers: enhanced photocatalytic activity based on photoinduced interfacial charge transfer. Nanoscale 5, 606-618 (2013). 
45. Zak, A. et al. Alkali metal intercalated fullerene-like $\mathrm{MS}_{2}(\mathrm{M}=\mathrm{W}, \mathrm{Mo})$ nanoparticles and their properties. J. Am. Chem. Soc. 124, 4747-4758 (2002).

46. Li, H. et al. Amorphous nickel-cobalt complexes hybridized with 1T-phase molybdenum disulfide via hydrazine-induced phase transformation for water splitting. Nat. Commun. 8, 15377 (2017).

47. Cheng, Y. et al. Origin of the phase transition in lithiated molybdenum disulfide. ACS Nano 8, 11447-11453 (2014).

48. Pandit, B. \& Chudasama, U. Synthesis, characterization and application of an inorgano organic material: p-chlorophenol anchored onto zirconium tungstate. Bull. Mater. Sci. 24, 265-271 (2001).

49. Xu, X. L., Schmalle, H. W. \& Giinter, J. R. Crystal structure of a hexagonal tin tungsten bronze prepared by a mild reaction. Solid State Ion. 76, 221-228 (1995).

50. Albert, C. F. \& Geoffery, W. Advanced inorganic chemistry: a comprehensive text. 3rd ed. (John Wiley, New York, 1972).

51. Lv, Y. Y. et al. Composition and temperature-dependent phase transition in miscible $\mathrm{Mo}_{1-x} \mathrm{~W}_{x} \mathrm{Te}_{2}$ single crystals. Sci. Rep. 7, 44587 (2017).

52. Gong, Y. et al. Band gap engineering and layer-by-layer mapping of seleniumdoped molybdenum disulfide. Nano Lett. 14, 442-449 (2014).

53. Wu, M., Cao, C. \& Jiang, J. Z. Light non-metallic atom (B, N, O and F)-doped graphene: a first-principles study. Nanotechnology 21, 505202 (2010).

54. Katagiri, Y. et al. Gate-tunable atomaically thin lateral $\mathrm{MoS}_{2}$ schottky junction patterned by electron beam. Nano Lett. 16, 3788-3794 (2016).

55. Yu, Y.-J. et al. Tuning the graphene work function by electric field effect. Nano Lett. 9, 3430-3434 (2009).

56. Su, W. S., Chen, Y. F., Hsiao, C. L. \& Tu, L. W. Generation of electricity in GaN nanorods induced by piezoelectric effect. Appl. Phys. Lett. 90, 063110 (2007).

57. Li, Y. et al. Lateral and vertical two-dimensional layered topological insulator heterostructures. ACS Nano 9, 10916-10921 (2015).

58. Lopez-Sanchez, O., Lembke, D., Kayci, M., Radenovic, A. \& Kis, A. Ultrasensitive photodetectors based on monolayer $\mathrm{MoS}_{2}$. Nat. Nanotechnol. 8, 497-501 (2013).

59. Shim, J. et al. High-performance $2 \mathrm{D}$ rhenium disulfide $\left(\mathrm{ReS}_{2}\right)$ transistors and photodetectors by oxygen plasma treatment. Adv. Mater. 28, 6985-6992 (2016).

60. Song, X. et al. Boosting two-dimensional $\mathrm{MoS}_{2} / \mathrm{CsPbBr}_{3}$ photodetectors via enhanced light absorbance and interfacial carrier separation. ACS Appl. Mater. Interfaces 10, 2801-2809 (2018).

61. Ma, C. et al. Heterostructured $\mathrm{WS}_{2} / \mathrm{CH}_{3} \mathrm{NH}_{3} \mathrm{PbI}_{3}$ photoconductors with suppressed dark current and enhanced photodetectivity. Adv. Mater. 28, 3683-3689 (2016).

62. Lee, Y. et al. High-performance perovskite-graphene hybrid photodetector. Adv. Mater. 27, 41-46 (2015).

63. Dang, V. Q. et al. Methylammonium lead iodide perovskite-graphene hybrid channels in flexible broadband phototransistors. Carbon 105, 353-361 (2016).

64. Kim, J. S., Yoo, H. W., Choi, H. O. \& Jung, H. T. Tunable volatile organic compounds sensor by using thiolated ligand conjugation on $\mathrm{MoS}_{2}$. Nano Lett. 14, 5941-5947 (2014).

65. Calvi, A., Ferrari, A., Sbuelz, L., Goldoni, A. \& Modesti, S. Recognizing physisorption and chemisorption in carbon nanotubes gas sensors by double exponential fitting of the response. Sensors 16, 731-739 (2016).

66. Liu, X. et al. Segregation growth of graphene on $\mathrm{Cu}-\mathrm{Ni}$ alloy for precise layer control. J. Phys. Chem. C. 115, 11976-11982 (2011).

67. Sanville, E., Kenny, S. D., Smith, R. \& Henkelman, G. Improved grid-based algorithm for bader charge allocation. J. Comput. Chem. 28, 899-908 (2007).

68. Bucko, T., Hafner, J., Lebegue, S. \& Angyan, J. G. Improved description of the structure of molecular and layered crystals: Ab initio DFT calculations with van der Waals corrections. J. Phys. Chem. A 114, 11814-11824 (2010).
69. Grimme, S. Semiempirical GGA-type density functional constructed with a long-range dispersion correction. J. Comput. Chem. 27, 1787-1799 (2006).

70. Momma, K. \& Izumi, F. VESTA3 for three-dimensional visualization of crystal, volumetric and morphology data. J. Appl. Crystallogr. 44, 1272-1276 (2011).

\section{Acknowledgements}

This research was supported by the National Natural Science Foundation of China (Grant no. 51322202 and 21373112), the Joint Research Fund for Overseas Chinese, Hong Kong and Macao Scholars (Grant no. 51528201) and the Young 1000 Talents Global Recruitment Program of China. Q.W. and X. Huang are grateful to the High Performance Computing Center of Nanjing Tech University for providing the computational resources. H.Z. thanks the support from MOE under AcRF Tier 2 (ARC 19/15 No. MOE2014-T2-2-093; MOE2015-T2-2-057; MOE2016-T2-2-103) and AcRF Tier 1 (2016-T1-001-147; 2016-T1-002-051), and NTU under Start-Up Grant (M4081296.070.500000) in Singapore. H.Z. also would like to acknowledge the Facility for Analysis, Characterization, Testing and Simulation, Nanyang Technological University, Singapore, for use of their electron microscopy facilities.

\section{Author contributions}

X. Huang and W.H. proposed the research direction and guided the project. Xiaoshan Wang and Z.W. designed and performed the experiments. J.Z., H.L., X. Hu, J.Q., G.H., and S.L. analyzed and discussed the experimental results. Xiang Wang, Z. Zhang, J.W. Z. Zhu, Z.L., Y.L., N.W., and B.C. performed some supporting experiments. Q.W. provided theoretical calculations and analyses. S.L., Q.H., J.C., J.Y., W.Z., T.H., and H.Z. contributed to the revision of the manuscript.

\section{Additional information}

Supplementary Information accompanies this paper at https://doi.org/10.1038/s41467018-06053-z.

Competing interests: The authors declare no competing interests.

Reprints and permission information is available online at http://npg.nature.com/ reprintsandpermissions/

Publisher's note: Springer Nature remains neutral with regard to jurisdictional claims in published maps and institutional affiliations.

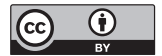

Open Access This article is licensed under a Creative Commons Attribution 4.0 International License, which permits use, sharing, adaptation, distribution and reproduction in any medium or format, as long as you give appropriate credit to the original author(s) and the source, provide a link to the Creative Commons license, and indicate if changes were made. The images or other third party material in this article are included in the article's Creative Commons license, unless indicated otherwise in a credit line to the material. If material is not included in the article's Creative Commons license and your intended use is not permitted by statutory regulation or exceeds the permitted use, you will need to obtain permission directly from the copyright holder. To view a copy of this license, visit http://creativecommons.org/ licenses/by/4.0/.

(C) The Author(s) 2018 